Hydrol. Earth Syst. Sci. Discuss., doi:10.5194/hess-2016-540, 2016

Manuscript under review for journal Hydrol. Earth Syst. Sci.

Published: 21 October 2016

\title{
Retrieval of rainfall fields in urban areas using attenuation measurements from mobile phone networks: A modeling feasibility study
}

\author{
5 Bahtiyor Zohidov ${ }^{1}$, Hervé Andrieu ${ }^{2}$, Myriam Servières ${ }^{1}$, Nicolas Normand ${ }^{3}$ \\ ${ }^{1}$ National School of Architecture, Ecole Centrale de Nantes, Nantes Cedex 3, 44321 France \\ ${ }^{2}$ IFSTTAR/IRSTV Nantes, Nantes Cedex 3, 44321 France \\ ${ }^{3}$ IRCYYN, PolyTech Nantes, Nantes, 44300 France
}

Correspondence addressed to: Bahtiyor Zohidov (bahtiyor.zohidov@eleves.ec-nantes.fr)

\begin{abstract}
Rainfall monitoring is an important global issue in urban hydrological applications, such as flood warning and water resources management systems. Until the present time, rain gauges and weather radars have been widely used as sensors to provide rainfall information with a detailed resolution; most cities in the world however are inadequately equipped.

15 Recently, commercial microwave links (MWL) have been proposed as a new means of monitoring space-time rainfall. A transmitted signal along such links is known to be attenuated by rainfall, hence the measurement of this signal attenuation could serve to estimate path-averaged rainfall intensity. The density of commercial MWL is typically high in most cities today, which raises new questions over the possibility of retrieving rainfall using signal attenuation data from multiple links. The objective of this article is to assess the feasibility of retrieving rainfall fields in urban areas using rain attenuation data

20 from commercial MWL that are mainly operated by mobile phone companies. This work is based on a simulation framework applied to a real case study. The study area is the city of Nantes, France. Rainfall datasets containing 207 weather radar images recorded by the Météo-France Agency's C-band at high spatial ( $250 \mathrm{~m}$ x $250 \mathrm{~m}$ ) and temporal (5 min) resolutions are first used to generate rain attenuation data over the existing mobile phone network, which combines 256 microwave links operating at 18, 23 and $38 \mathrm{GHz}$. The rain attenuation data generated are used as a real signal dataset. A novel retrieval

25 algorithm is then proposed to convert the rain-induced attenuation data into a rainfall map. A priori knowledge introduced to initialize the algorithm heavily influences retrieval performance if the problem to be solved is under-determined, as is the case herein.

The capabilities as well as limitations of the retrieval algorithm, as regards capturing different rainfall variability, are evaluated. A detailed sensitivity analysis, carried out with respect to various parameters including a priori knowledge,

30 decorrelation distance, and the retrieval performance of the algorithm depending on the density level of the MWL network is also evaluated in a light rain, a shower and amidst storm events. The conclusion, based on 200+ retrieval tests, states that the
\end{abstract}


Hydrol. Earth Syst. Sci. Discuss., doi:10.5194/hess-2016-540, 2016

Manuscript under review for journal Hydrol. Earth Syst. Sci.

Published: 21 October 2016

proposed algorithm is capable of capturing high rainfall variability in the presence of large measurement error sources according to the adopted methodology.

Keywords: Rainfall Retrieval, Microwave Link, Attenuation, Inverse Method.

\section{Introduction}

Rainfall may constitute an obstacle to radio wave propagation in the atmosphere at frequencies ranging from 5 to $50 \mathrm{GHz}$ (Hogg, 1968; Atlas \& Ulbrich, 1977). This inconvenience offers new opportunities to measure rainfall. The measurement of rainfall rates using radio links set up by phone companies has become an active research topic. These links mainly operate at

10 frequencies attenuated by rainfall; moreover, measuring the path-integrated attenuation between the link transmitter and receiver could yield the mean rainfall rate along this path, as suggested by (Upton, et al., 2005; Messer, et al., 2006; Leijnse, et al., 2007). Several experiments, conducted in very different contexts, have confirmed these results: (Doumounia, et al., 2014) obtained encouraging results in Sahelian West Africa along a 29-km link at $7 \mathrm{GHz}$; (Fenicia, et al., 2012) tested different analysis methods on two dual-frequency links in Luxemburg City; (Ostrometzky, et al., 2015) proposed a method that allows estimating all types of precipitation quantities. Recent experiments, involving larger datasets recorded on a greater number of telecommunication links and validation by rainfall measurement devices (rain gauges, disdrometers), have provided robust assessments of these initial findings (Overeem, et al., 2011; Rayitsfeld, et al., 2012).

These promising results must not neglect however the presence of several sources of errors, whose influence has been studied by the following authors: small-scale variability of rainfall along the links (Berne \& Uijlenhoet, 2007), attenuation due to wet antennae (Leijnse, et al., 2007), spatial variations in DSD (Drop Size Distribution) along the link (Leijnse, et al., 2010; Zinevich, et al., 2010), all of which present a very comprehensive study of the various sources of error and uncertainty.

Telecommunication links might also be used to improve the operations of conventional rainfall measurement devices: detection of malfunctioning rain gauges in urban areas (Bianchi, et al., 2013), determination of the mean field adjustment of weather radar data (Cummings, et al., 2009), and the detection and correction of attenuated radar data (Rahimi, et al., 2006). One important and interesting aspect is the mapping of rainfall fields from path-integrated attenuation measured on a network of telecommunication links. This subject was first addressed by (Giuli, et al., 1991), who proposed a "microwave tomographic inversion technique" that considers rainfall fields as a linear combination of basis functions. The authors also tested the method within the academic framework of simulated rainfall fields sampled by a regular network of radio links.

30 Their method has since been further improved: (Giuli, et al., 1999; Cuccoli, et al., 2011) proposed reconstructing rainfall fields from path-integrated attenuation measurements on radio communication links by means of a tomographic processing 
Hydrol. Earth Syst. Sci. Discuss., doi:10.5194/hess-2016-540, 2016

method referred to as the "Combined Deterministic-Stochastic Retrieval Technique". These authors obtained valuable results when testing their method using a simulation approach applied to a real case study, namely rainfall fields observed by radar and the actual linked network of the city of Florence (Italy). (Zinevich, et al., 2008) used the SIRT, i.e. the simultaneous iterative reconstruction technique described by (Kak \& Slaney, 1988), to reconstruct rainfall fields in a study area equipped

5 without spatial regularity or frequency homogeneity. (Zinevich, et al., 2009) combined a space-time advection model of rainfall with an extended Kalman filter (Welch \& Bishop, 2006) to perform the retrieval from path-integrated attenuation measurements. (Goldshtein, et al., 2009) proposed a stochastic interpolation algorithm based on the Inverse Distance Weighting function (Shepard, 1968) to reconstruct rainfall fields over a sparse and arbitrary cellular network geometry. Most of the cited studies were intended to retrieve rainfall in urbanized areas well equipped with telecommunications links. On a

10 very different scale, (Overeem, et al., 2013) implemented an extensive network of 2,400 links to retrieve the space-time dynamics of rainfall for the $35,500 \mathrm{~km}^{2}$ of the Netherlands, by interpolating the rainfall estimates derived at link locations using the Kriging method (Creutin \& Obled, 1982).

(Gosset, et al., 2015) emphasized the potential benefit of commercial MWL for mapping rainfall in areas with poor or nonexistent coverage offered by conventional measurement devices (e.g. rain gauge, weather radar), including in urban

15 areas. This article addresses the special case of cities well equipped with MWL operated by telecommunications companies. A small number of studies have been devoted to reconstructing rainfall fields from path-integrated attenuation on these links; the feasibility of this reconstruction process has not yet been fully established. In the follow-up to (Cuccoli, et al., 2011), the objective has been to assess the feasibility of estimating rainfall fields from attenuation measurements on microwave communication links by means of a simulation approach based on a real-world case study. The series of observed weather

20 radar images, recorded at a very high spatial $(250 \mathrm{~m})$ and temporal (several minutes) resolution, are used to simulate attenuation measurements along the communication links of the Nantes metropolitan area. These attenuation "data" will then be applied to retrieve the rainfall field by running an inverse algorithm. The retrieval efficiency will be evaluated by comparing the observed and retrieved rain fields. A highly detailed analysis of sensitivity to influential factors (i.e. available data and associated errors, inverse algorithm, a priori information, spatial and temporal rain field structure, communication

25 link network geometry) will be performed in order to assess the feasibility of the proposed method. Section 2 will present the case study under consideration as well as the simulation of path-integrated attenuation measurements. Section 3 will then discuss the method used to retrieve rainfall fields and its application conditions in the case of the studied problem. The results obtained and a sensitivity analysis conducted on these results will be addressed in Section 4.

\section{Methodology description}

30 This section will present both the problem raised by the retrieval of rain rate maps from path-attenuated measurements on an MWL network covering an urban area extensively. The corresponding attenuation model will be formulated in Subsection 2.1, while Subsection 2.2 will examine the inverse algorithm used to solve this retrieval problem, by relying on the works of 
Hydrol. Earth Syst. Sci. Discuss., doi:10.5194/hess-2016-540, 2016

Manuscript under review for journal Hydrol. Earth Syst. Sci.

Published: 21 October 2016

(c) Author(s) 2016. CC-BY 3.0 License.

(Menke, 1989) and (Tarantola \& Valette, 1982a). Subsection 2.3 will present the conditions for applying this algorithm to the problem at hand.

\subsection{Path-integrated attenuation by a network of microwave links}

Microwave attenuation by rainfall along a link path can be expressed as:

$5 \quad \mathrm{~A}_{1}=\int_{\mathrm{T}_{1}}^{\mathrm{R}_{1}} \mathrm{a}_{1} \mathrm{R}(\mathrm{u})^{\mathrm{b}_{1}} \mathrm{du}$

with $A_{1}$ being the path-integrated attenuation (hereafter denoted PIA) along link $1,\left(T_{1}, R_{l}\right)$ the transmitter and receiver coordinates of this link, $\mathrm{R}(\mathrm{u})$ the rainfall intensity at location $\mathrm{u}$, and $\left(\mathrm{a}_{1}, \mathrm{~b}_{\mathrm{l}}\right)$ the parameters of an attenuation law dependent on the link wavelength, polarization, temperature and ultimately on the DSD of rainfall (Olsen, et al., 1978).

Let the rainfall field be defined as a pixelated image, e.g. a weather radar image, then Eq. (1) can be expressed as follows:

$10 \quad A_{1}=a_{1} \sum_{j=1}^{j=n(l)} L_{k(1, j)} R_{k(1, j)}^{b_{1}}$

where $\mathrm{n}(\mathrm{l})$ is the number of pixels in the rain image crossed by link $1, L_{k(1, j)}$ the path length of link $l$ in pixel $k(l, j)$ of the rain image, and $R_{k(j)}$ the rainfall intensity in pixel $k(j, l)$. The function $k(l, j)$ serves to associate the rain image pixels with the MWL that cross them.

Considering that the MWL network contains N links, the overall model relating the PIA on all the links to the pixelated rain

15 image can be written as:

$A=m(R)+\varepsilon$

where $\mathrm{A}=\left[\begin{array}{llll}\mathrm{A}_{1} & \ldots \ldots & \ldots & \mathrm{A}_{\mathrm{N}}\end{array}\right]$ is the vector combining the PIA on all $\mathrm{N}$ links, $\mathrm{R}=\left[\mathrm{R}_{1}\right.$ $\mathrm{R}_{\mathrm{M}}$ ] the vector combining the rainfall rate on the $\mathrm{M}$ rain field pixels crossed by a link, and $\varepsilon=\left[\begin{array}{llll}\varepsilon_{1} & \ldots \ldots & \ldots & \varepsilon_{\mathrm{N}}\end{array}\right]$ the vector combining the modeling errors on all $\mathrm{N}$ links. Let's note that the rain pixels involved in model $\mathrm{m}$ do not comprise all rain image pixels. The number of uncrossed pixels depends on the microwave link characteristics and the spatial resolution, $\Delta=\Delta \mathrm{x}=\Delta \mathrm{y}$, of the rain pixels, which are assumed to be square.

\subsection{The identification algorithm}

The objective of this algorithm is to retrieve the rainfall field that best reconstitutes the measured PIA values of the MWL network according to the model defined by Eq. (4). The method chosen to solve this inverse problem is the conventional inverse approach, as detailed in (Menke, 1989), while the algorithm used in this work is the one proposed by (Tarantola \& Valette, 1982a). The solution minimizes the following expression:

$\Phi(\boldsymbol{A}, \boldsymbol{R})=\left[\boldsymbol{A}-\boldsymbol{A}_{0}\right]^{t} \boldsymbol{C}_{A}^{-1}\left[\boldsymbol{A}-\boldsymbol{A}_{0}\right]+\left[\boldsymbol{R}-\boldsymbol{R}_{0}\right]^{t} \boldsymbol{C}_{R}^{-1}\left[\boldsymbol{R}-\boldsymbol{R}_{\mathbf{0}}\right]$

$\boldsymbol{A}=m(\boldsymbol{R})$ 
Hydrol. Earth Syst. Sci. Discuss., doi:10.5194/hess-2016-540, 2016

Manuscript under review for journal Hydrol. Earth Syst. Sci.

Published: 21 October 2016

(c) Author(s) 2016. CC-BY 3.0 License.

where $\Phi$ is the likelihood function, $\mathrm{t}$ signifies transpose, $\boldsymbol{A}_{0}$ denotes the vector of measured PIA values, $\boldsymbol{R}_{\mathbf{0}}$ is the $a$ priori rainfall rate on the pixels crossed by a microwave link, and $\boldsymbol{C}_{\boldsymbol{A}}$ and $\boldsymbol{C}_{\boldsymbol{R}}$ are the covariance matrices of residuals between truth and $a$ priori values of $\boldsymbol{A}$ and $\boldsymbol{R}$, respectively. The statistical distributions of both $\left[\boldsymbol{A}-\boldsymbol{A}_{0}\right]$ and $\left[\boldsymbol{R}-\boldsymbol{R}_{\mathbf{0}}\right]$ are assumed to be unbiased and Gaussian. (Menke, 1989) demonstrated that the solution vector $\boldsymbol{R}^{\prime}$ satisfies:

$5 \quad \boldsymbol{R}^{\prime}=\boldsymbol{R}_{\mathbf{0}}+\boldsymbol{C}_{\boldsymbol{R}} \boldsymbol{M}^{t}\left[\boldsymbol{M}^{t} \boldsymbol{C}_{\boldsymbol{R}} \boldsymbol{M}+\boldsymbol{C}_{\boldsymbol{A}}\right]^{-1}\left[\boldsymbol{A}_{\mathbf{0}}-m\left(\boldsymbol{R}^{\prime}\right)+\boldsymbol{M}\left(\boldsymbol{R}^{\prime}-\boldsymbol{R}_{\mathbf{0}}\right)\right]$

Where $\boldsymbol{M}$ is the matrix of (first-order) partial derivatives of model $m$. If model $m$ is nonlinear, Eq. (5) can then be solved using an iterative method, i.e.:

$\boldsymbol{R}_{k+1}=\boldsymbol{R}_{\mathbf{0}}+\boldsymbol{C}_{\boldsymbol{R}} \boldsymbol{M}_{\boldsymbol{k}}^{\boldsymbol{t}}\left[\boldsymbol{M}_{\boldsymbol{k}}^{\boldsymbol{t}} \boldsymbol{C}_{\boldsymbol{R}} \boldsymbol{M}_{\boldsymbol{k}}+\boldsymbol{C}_{\boldsymbol{A}}\right]^{-1}\left[\boldsymbol{A}_{\mathbf{0}}-m\left(\boldsymbol{R}_{k}\right)+\boldsymbol{M}_{\boldsymbol{k}}\left(\boldsymbol{R}_{k}-\boldsymbol{R}_{\mathbf{0}}\right)\right]$

in which $\boldsymbol{R}_{\boldsymbol{k}}$ constitutes the result of the $\mathrm{k}^{\text {th }}$ iteration and $\boldsymbol{M}_{\boldsymbol{k}}$ the matrix of partial derivatives of model $m$ at point $\boldsymbol{R}_{\boldsymbol{k}}$. Further

10 information about the stability, convergence and uniqueness of the solution of such nonlinear problems can be found in Chapter 9 of (Menke, 1989) and in Tarantola and Valette (1982a and b). The general case of inverse problems involving non-Gaussian statistics has been addressed by (Tarentola, 1987).

\subsection{Remarks}

Before applying this algorithm to the retrieval of rainfall fields using PIA measurements from an MWL network, let's consider the a priori information and nature of the studied problem. The a priori information is composed of: i) the vector $\boldsymbol{A}_{\mathbf{0}}$ and its covariance matrix $\boldsymbol{C}_{\boldsymbol{A}}$, which characterize the level of confidence in the data; and ii) the vector $\boldsymbol{R}_{\mathbf{0}}$ and its covariance matrix $\boldsymbol{C}_{\boldsymbol{R}}$, which contain initial knowledge of the parameters to be identified (i.e. rainfall field) and the level of confidence ascribed to this knowledge. The solution output by the inverse algorithm results from a compromise between two extreme states: i) a solution that perfectly fits the observed data through the theoretical model; and ii) a solution remaining very close to the a priori information on the parameters. The assistance provided by this a priori information actually depends on the nature of the problem. If the observed data are insufficient or if confidence in the data is weak, the problem is then considered underdetermined and the a priori information assumes a dominant role. On the other hand, if the problem is over-determined (i.e. very high quality data in sufficient quantity), the solution no longer depends on the $a$ priori information. The special case of rainfall field retrieval from PIA measurements in an MWL network depends on several factors:

- The MWL network heterogeneously covers the study area, as illustrated in Figure 1, which shows that the link density decreases from the city center out to the suburbs;

- The spatial resolution adopted to represent the rainfall field complicates to some extent problem resolution. Depending on this spatial information, the number of pixels uncrossed by one or more links may vary substantially. Yet the increased pixel size can lead to a loss of representativeness if the rainfall field displays strong spatial variability. 
Hydrol. Earth Syst. Sci. Discuss., doi:10.5194/hess-2016-540, 2016

Manuscript under review for journal Hydrol. Earth Syst. Sci.

Published: 21 October 2016

In summary, it appears that the problem to solve is "heterogeneously" determined and that both practical implementation of the algorithm and choice of the a priori information are capable of significantly influencing the solution.

\section{Application of the retrieval algorithm}

This section will present the conditions for applying the algorithm to retrieve the rainfall field in an urban area through use of a dense MWL network.

\subsection{Attenuation data and associated covariance matrix}

The errors associated with the attenuation measurement along HF links and the rainfall rate estimation from these measurements have been modeled by (Zinevich, et al., 2010) and studied in detail by (Leijnse, et al., 2010). The vector $\boldsymbol{A}_{\mathbf{0}}$ encompasses PIA measurements on the $N$ links. The attenuation measurements are assumed to be mutually independent.

10 Consequently, the covariance matrix $\boldsymbol{C}_{\boldsymbol{A}}$ is assumed to be diagonal, with its diagonal term being expressed as:

$\operatorname{cov}\left(A_{i}, A_{j}\right)=0$ if $i \neq j$ and $\operatorname{cov}\left(A_{i}, A_{i}\right)=\sigma_{A i}^{2}$ with $\sigma_{A i}=\alpha A_{i}+0.01$

with the $\alpha$ parameter being equivalent to the coefficient of variation of the statistical distribution of the assumed measurement error (Zinevich, et al., 2010) on the PIA values; the 0.01 constant has been added to prevent the matrix from becoming singular.

\section{$15 \quad 3.2$ A priori values of rainfall}

The a priori knowledge on model parameters is described by the rainfall rate vector $\boldsymbol{R}_{\mathbf{0}}$ and its covariance matrix $\boldsymbol{C}_{\boldsymbol{R}}$. The selected approach consists of deducing the a priori rainfall at rain pixel $i$ from the measured PIA values on the links closest to this location, i.e.:

$R_{0 i}=\frac{1}{n_{l}} \sum_{j=1, n_{i}} R_{j}$ with $R_{j}=\left[\frac{A_{0 k(j)}}{a_{k(j)}}\right]^{-b_{k(j)}}$

20 where $n_{l}$ is the number of considered links; $A_{0 k(j)}$ the measured PIA on link $k(j)$, which is one of the $n_{l}$ links closest to pixel $i$; and $a_{k(j)}$ and $b_{k(j)}$ are parameters of an $R$-A relationship adapted to link $k(j)$. The distance between a link and a pixel is derived from the orthogonal projection of the pixel (i.e. center) on the link.

The a priori error variance of $R_{0} i$ is estimated from the variance of the $n_{l}$ values of $R_{j}$ used to estimate $R_{0} i$; it is expressed as:

$25 \sigma_{R i}^{2}=\frac{1}{n_{l}-1} \sum_{j=1, n_{i}}\left[R_{j}-R_{0 i}\right]^{2}$

and the terms of the a priori covariance matrix $\boldsymbol{C}_{\boldsymbol{R}}$ are estimated by: 
Hydrol. Earth Syst. Sci. Discuss., doi:10.5194/hess-2016-540, 2016

Manuscript under review for journal Hydrol. Earth Syst. Sci.

Published: 21 October 2016

(c) Author(s) 2016. CC-BY 3.0 License.

$\operatorname{cov}\left(R_{0 i}, R_{0 j}\right)=\sigma_{R_{i}} \sigma_{R j} \exp \left(\frac{d_{i j}^{2}}{D^{2}}\right)$

with $d_{i j}$ being the distance between rain pixels $i$ and $j$, and the D parameter controlling the decorrelation between errors on the $a$ priori rain rates.

It is observed that the number $n_{l}$ of the closest selected links assumes significant importance during algorithm initialization.

5 Let's consider that at $n_{l}=5$, the initialization remains very local. The maximum value of $n_{l}$ equals the total number of study area links, hence each rain pixel is assigned the same a priori value (and error variance), which is equal to the mean value and the variance of the rainfall field derived from the measured PIAs. Moreover, let's note that the initialization is not homogeneous over the entire study area since the neighborhood corresponding to the $n_{l}$ closest links depends on the link density.

\section{$10 \quad 3.3$ Application of the algorithm - Grid nesting procedure}

Subsection 2.3 pointed out that available information decreases from the city center to the suburbs. In order to take into account this specific feature, it is proposed herein to apply the identification algorithm under the following conditions: i) the pixels of the rain field targeted by the identification are merely those crossed by MWL; and ii) the pixel area is adapted to the MWL density.

15 The identification algorithm is then implemented according to the following grid nesting procedure:

Step 1: Rain field retrieval is performed first at a low spatial resolution $\left(2 \times 2 \mathrm{~km}^{2}\right)$ over the largest possible geographic area covered by the link network;

Step 2: The solution obtained serves as a priori for the rain field retrieval at an improved spatial resolution $\left(1 \times 1 \mathrm{~km}^{2}\right)$ over a subarea limited to the pixels crossed by the links at this level of resolution. During this step, the uncrossed pixels retain the values assigned in the previous step and remain a solution;

Step 3: This procedure can ultimately be repeated to further improve the spatial resolution in once again restricting the subarea to the remaining crossed pixels. At this point in our case, the spatial resolution is set at $0.5 \times 0.5 \mathrm{~km}^{2}$, which is acceptable as a final spatial resolution of the retrieval process.

Practically speaking, this iterative grid nesting procedure calls for refining rainfall field retrieval as the link density

25 increases. The iterative procedure explained above is illustrated in Figure 2.

\section{Presentation of the case study: City of Nantes}

This study seeks to assess the feasibility of retrieving rainfall fields in urban areas from existing MWL deployed by telecommunications companies. Our case study is based on the situation in the city of Nantes. 
Hydrol. Earth Syst. Sci. Discuss., doi:10.5194/hess-2016-540, 2016

\subsection{Microwave links}

The city of Nantes, France is covered with a set of MWL owned by the four mobile communications companies operating in France. At the end of 2012, the urbanized part of this city was equipped with a total of 256 MWL (www.cartoradio.fr) operating at 18, 23 and $38 \mathrm{GHz}$ (as shown in Fig. 1). The lengths of these microwave links range from 0.3 to $16.8 \mathrm{~km}$, with

5 an average of $4.2 \mathrm{~km}$. The main characteristics of this set of links are detailed in Table 1. The rows labeled "count", "mean", "min" and "max" list respectively the number of microwave links, their average, minimum and maximum lengths. Within the network service area, nearly $95 \%$ of the MWL at $38 \mathrm{GHz}$ are shorter than $5 \mathrm{~km}$. This same percentage threshold reveals almost $11 \mathrm{~km}$ and $10 \mathrm{~km}$ for the links at 18 and $23 \mathrm{GHz}$, respectively. These data provide a clear indication of the fact that microwave link lengths at higher frequencies are basically assumed to be shorter and vice versa. At all frequencies, the minimum lengths are practically the same, i.e. at less than $1 \mathrm{~km}$.

\subsection{Classification of microwave link density}

It is important to define the density level of the microwave link network, as this parameter allows differentiating between dense and sparse regions within the study area. The reason for such a distinction is to understand the influence of network topology on rainfall retrieval accuracy. The density level of the MWL network has therefore been computed. The result of this computation will be called a "pixel density map", which can then be used to validate network system performance across various regions involved in the rainfall retrieval process.

A basic assumption herein is that the higher link density should yield more weight on the surface. The following expression is introduced to obtain the $i^{\text {th }}$ pixel area density:

$W_{i}=\sum_{j=1}^{m} \frac{l_{j i}}{L_{j}}$

20 where $j$ is the link index, $i$ the pixel index, $m$ the number of links, W the pixel density vector, $l$ the length of the intersected part of link $L$ (in km). If Eq. (11) were applied to all pixels crossed by microwave links, the pixel density vector would be obtained. This vector could then be reshaped into a two-dimensional pixel density map.

Figure 3 shows a histogram of the pixel density computed over $256 \mathrm{MWL}$ within the study area. The distribution of W in this figure is heavily right-skewed, indicating that the average value of $\mathrm{W}$ is greater than its median. The density level is considered "low" if the condition $W<W_{\text {median }}$ is satisfied; in our case, $W_{\text {median }}=0.5$. Similarly, the density level is considered "moderate" if W lies between 0.5 and 1 . Beyond the moderate level, density is considered sufficiently "high" since it is assumed to be acceptable if some $30 \%$ of $\mathrm{W}$ values exceed 1 . However, this percentage depends on the user's choice. Figure 4 shows the pixel density map derived at a $2 \times 2 \mathrm{~km}^{2}$ resolution (i.e. pixel size) over the entire MWL network area. Note that the density levels are classified in the colors gray, red and blue, which represent low, moderate and high density regions of the MWL network, respectively. 
Hydrol. Earth Syst. Sci. Discuss., doi:10.5194/hess-2016-540, 2016

Manuscript under review for journal Hydrol. Earth Syst. Sci.

Published: 21 October 2016

(c) Author(s) 2016. CC-BY 3.0 License.

\subsection{Rainfall data}

Rainfall data have been provided by the C-band weather radar at Treillières, with a 3-dB beam width equal to 1.25 deg. This radar station, located $10 \mathrm{~km}$ north of Nantes, is labeled as "C-Band" in Figure 1. Radar images are available at 5-min intervals, with an area size of a $128 \mathrm{~km}$ x $128 \mathrm{~km}$ Cartesian grid at a spatial resolution of $250 \mathrm{~m}$ x $250 \mathrm{~m}$. Since the radar image size (i.e. $128 \mathrm{~km}$ x $128 \mathrm{~km}$ ) is larger than the study region, only a $40 \mathrm{~km}$ x $40 \mathrm{~km}$ piece has been selected, which is sufficient to cover the area of microwave links. For purposes of illustration, the radar rain maps for each considered event are displayed in Figure 5.

A total of 34 rain periods recorded between 2009 and 2012 have been selected for this study. According to (Emmanuel, et al., 2012), the days of recordings were partitioned into four groups of different rainfall field types. Thanks to a

10 meteorological analysis combined with radar image visualization, three categories of meteorological situations could be detected at the mesoscale: warm sectors, fronts, and the tail end of low pressure systems. These situations yield four distinct types of rainfall fields, namely: 1) light rain (correlated with warm sectors), 2) storms organized in rain bands (correlated with fronts), 3) storms less well organized (correlated with fronts), and 4) showers (correlated with the tail end of low pressure systems). (Emmanuel, et al., 2012) studied the spatial variability of these 4 types of rainfall, which display distinct characteristics in terms of intermittency and rain variability. In our study, 7 rain events were extracted from these periods by collating a total of 207 rainfall maps, representing these 4 rainfall types characterized by different spatial and temporal variabilities. Descriptions of the duration, period and number of rainfall maps for each event are provided in Table 2.

\subsection{Path-Integrated Attenuation data}

To generate PIA data over the given MWL network, the following steps have been performed:

- Extract a rainfall map of weather radar and superimpose it on the study area. In this case, the pixel index of the rainfall map is expected to be the same as the index of the discretized area;

- Compute the PIA along each link using Eq. (3) in the presence of measurement error $\varepsilon$. The a and b coefficients of the PIA model in Eq. (3) at 18, 23 and $38 \mathrm{GHz}$ are obtained from (ITU-R, 2005);

- Quantize the computed PIA at a 0.1-dB resolution.

25 The output of the above steps is to be substituted for the real rain attenuation data potentially obtained from telecommunications companies. The sources of error during the rain attenuation measurement process are twofold: i) the PIA model (Eq. 3); and ii) instrumental impairment such as quantization, antenna wetting and temperature, and gas effects. Since quantifying the error source with precision lies outside the scope of this paper, a simple approach is considered for simulating the nature of the real signal attenuation caused by rain. This approach has been introduced using a Gaussian 30 distributed random variable with variance equal to 5\% of PIA attenuation, as computed along each link of the MWL network. (Atlas \& Ulbrich, 1977) showed that uncertainties due to drop size distribution variability when determining the 
Hydrol. Earth Syst. Sci. Discuss., doi:10.5194/hess-2016-540, 2016

Manuscript under review for journal Hydrol. Earth Syst. Sci.

Published: 21 October 2016

(c) Author(s) 2016. CC-BY 3.0 License.

path-averaged rain rate increased from $10.8 \%$ to $39.7 \%$ as frequency decreased from 34.86 to $9.37 \mathrm{GHz}$. These authors found however that should the k-R relation be quasi-linear, i.e. $b \approx 1$, then this influence would be negligible, resulting in less than $10 \%$ average error. According to the authors, the k-R relation linearity reaches a peak at $35 \mathrm{GHz}$. This finding is clearly applicable to our case since the exponent values (i.e. b coefficient) in Eq. (3) at 18, 23 and 38 GHz are nearly 1 . More

5 recently, theoretical as well as experimental studies (Leijnse, et al., 2007; Leijnse, et al., 2010; Zinevich, et al., 2010) have also confirmed the findings reported by (Atlas \& Ulbrich, 1977). Higher percentages indicate that our confidence in the accuracy of rain attenuation measurement is lower. However, a higher percentage (i.e. 20\%) has also been tested to show that the attenuation measurement might be influenced by greater sources of error as well. Moreover, the signal quantization effects are introduced after computing rain attenuation in the presence of the PIA model-related error source. This 10 quantization error occurs when the signal is truncated at a certain level of precision. Typical precision values are 0.1 and 1 $\mathrm{dB}$, at which the actual signal becomes truncated. The signal quantization error variance remains uniform and equal to $\sigma_{\mathrm{q}}^{2}=$ $\frac{\Delta^{2}}{12}$ (Widrow \& Kollàr, 2008). The magnitude of the quantization effect has been well understood in a number of studies (Goldshtein, et al., 2009; Zinevich, et al., 2010), with this type of error source also exerting a significant influence on shorter links during lower-intensity rain events. The higher quantization value indicates less accuracy and precision inherent in the

15 antenna station equipment.

The steps described above are applied to generate the rain attenuation data and then repeated for all 207 rainfall maps. Figure 6 illustrates the attenuation dataset produced in light rain, showers, organized and unorganized storm events. The $y$ axis represents the average path-integrated attenuation values along each link derived on the 113, 26, 34 and 34 rainfall maps associated to those events, respectively. Here again, the data generated have been classified according to link length in 3

20 different ranges, namely $(0,2],(2,5]$ and $(5,17] \mathrm{km}$, which practically represent the percentile intervals of $(0,25 \%],(25 \%$, $50 \%]$ and $(50 \%, 75 \%]$ of all MWL lengths, respectively. This classification is useful in providing a deeper understanding of the rain attenuation variability derived depends on link length from one rain event to the next.

It is evident that the PIA value gradually increases with increasing link length and frequency. Another key finding is the rising trajectory of this value at higher rainfall variability, especially in the unorganized storm case (i.e. lower right figure), which reveals a "close-to-reality" type of measurement error sources. In this study, the simulated error sources added to the PIA measurement process generally reflect the nature of possible error sources discussed in experimental and theoretical studies (Atlas \& Ulbrich, 1977; Leijnse, et al., 2007; Leijnse, et al., 2008; Leijnse, et al., 2010). When the simulated standard deviations of error sources are analyzed (not discussed in this paper), it was found that the nature of the error simulated in this experiment is not properly replicated if link frequency variability is considered. This condition however can 30 be viewed as a limitation to simulating the nature of measurement error (Zinevich, et al., 2010) introduced in this study. 
Hydrol. Earth Syst. Sci. Discuss., doi:10.5194/hess-2016-540, 2016

Manuscript under review for journal Hydrol. Earth Syst. Sci.

Published: 21 October 2016

(c) Author(s) 2016. CC-BY 3.0 License.

\section{Sensitivity analysis}

The sensitivity analysis offers insight into understanding the interrelationships between algorithm parameters. The significance of algorithm sensitivity is to test the influence of various parameter values on the solution vector. In other words, the result of this sensitivity test reveals that the algorithm is either sensitive or insensitive to changes in algorithm parameter values.

In this section, the analysis of sensitivity to algorithm parameter values will be discussed. Subsection 5.1 will describe the sensitivity analysis protocol, while Subsection 5.2 will address the influence of the a priori parameters (i.e. $n_{l}$ and D) on rainfall retrieval.

\subsection{Sensitivity analysis protocol}

10 The overall structure of the sensitivity analysis testing the algorithm parameters is given in Figure 7. Levels 1 and 2 denote the values of sensitivity parameters to be tested, which consist of a priori rainfall selection $n_{l}$ and decorrelation distance $\mathrm{D}$, respectively. The Level 3 procedure is performed in the following order:

- Rainfall map: Extract the rainfall map from the weather radar. Map resolution is $250 \mathrm{~m}$ x $250 \mathrm{~m}$, as obtained from the radar data (see Section 4);

- Rain attenuation data generation: Rain attenuation data over the microwave link network are generated according to the procedure set forth in Subsection 4.3;

- Rainfall retrieval: The grid nesting procedure described in Subsection 3.1 is applied to perform rainfall retrieval;

- Comparison: The rainfall map retrieved by the proposed algorithm is compared with an observed radar rainfall map by employing the NSE criterion commonly used in the field of hydrology (Nash \& Sutcliffe, 1970), expressed as follows:

$$
N S E=1-\frac{\sum_{i=1}^{n}\left(R_{o b s}^{i}-R_{r e t}^{i}\right)^{2}}{\sum_{i=1}^{n}\left(R_{o b s}^{i}-\bar{R}_{o b s}\right)^{2}}
$$

The NSE criterion provides an overall assessment by taking into account both the observed $\left(R_{\text {obs }}\right)$ and retrieved $\left(R_{\text {ret }}\right)$ rainfall maps, with $\mathrm{n}$ being the number of pixels in the compared maps. The interval for NSE values lies between $-\infty$ and 1 : the closer the NSE value is to 1 , the more accurate the model retrieval.

25 Level 3 is applied to the 207 rainfall maps, which represent light rain, showers, organized and unorganized storm events. Let's note that each event has been tested and analyzed separately. This protocol helps determine the sensitivity of retrieval algorithm parameters to various types of rainfall. 
Hydrol. Earth Syst. Sci. Discuss., doi:10.5194/hess-2016-540, 2016

Manuscript under review for journal Hydrol. Earth Syst. Sci.

Published: 21 October 2016

\subsection{Sensitivity to the a priori parameters}

\subsubsection{Sensitivity to the $a$ priori rainfall map}

The objective here is to test the influence of the a priori rainfall. Each rain pixel is set at a value equal to the mean of the rainfall estimates, as derived from PIA values on the links closest to its location, i.e. $n_{l}$. These sensitivity tests pertain to the neighborhood with $n_{l}$ spanning a range that includes $5,7,10,15,100$ and 256, i.e. from a very local to the global neighborhood, respectively. Let's recall that the standard deviation in a priori variance associated with the a priori rainfall has been set at the variance of the considered rainfall estimates. Applying the sensitivity protocol described in Subsection 5.1 yields Figure 8, which illustrates the results of sensitivity to the a priori parameters. The red dots denote the highest NSE values, which indicate that the algorithm performs best with these choices. Increasing the values of $n_{l}$ certainly decreases

10 algorithm accuracy regardless of rainfall variability. One important feature found in these results however is that higher rainfall variability widens the optimum $n_{l}$ parameter value ranges (see, for example, the difference in the number of red dots between light rain and unorganized storm events).

\subsubsection{Sensitivity to the decorrelation distance of the a priori rainfall error}

The purpose here is to test the sensitivity of the retrieval algorithm to parameter D, see Eq. (10). The results of the analysis in

15 Figure 8 show that the algorithm is also sensitive to the value of D: it appears that the influence of D increases with rainfall variability. As opposed to the $n_{l}$ parameter, the optimal $\mathrm{D}$ value is found to lie in a tight range, i.e. very few choices, regardless of rainfall type.

\section{Evaluation}

This section will evaluate the capabilities and limitations of the proposed rainfall retrieval algorithm. A series of rainfall events recorded by weather radar are used as a basis to assess the proposed algorithm. This evaluation is performed at a 0.5 $\mathrm{km} \times 0.5 \mathrm{~km}$ resolution with respect to the optimum (selected) parameters of the algorithm given in Table 3 . The evaluation principle and conditions will first be described in Subsection 6.1; Subsection 6.2 will then discuss the results obtained.

\subsection{Evaluation principle}

The evaluation principle is defined as follows: i) an efficiency curve is calculated for each event (rainfall type) that allows assessing the retrieval performance of the algorithm vs. rainfall variability; and ii) the evaluation zone is classified in order to verify the retrieval efficiency in different regions of the MWL network (this process is performed based on the pixel density map given in Subsection 4.2).

The initial findings of this evaluation protocol consist of: a) an overall comparison between the retrieved (by the algorithm) and the observed (by weather radar) rainfall maps; and b) a separate analysis of the influence of the inverse algorithm and $a$ 
Hydrol. Earth Syst. Sci. Discuss., doi:10.5194/hess-2016-540, 2016

priori knowledge on retrieval performance. These features help understand the added value of a priori knowledge depending on rainfall variability. Subsequent findings stem from evaluating the method over the entire monitoring network system and evaluating retrieval efficiency on the basis of microwave link network density. This latter evaluation relies on the pixel density map (as detailed in Subsection 4.2), which depicts the microwave link density level.

\section{$5 \quad 6.2$ Evaluation results}

Regarding the initial findings of our analysis, examples of retrieved rainfall for light rain, showers, organized and unorganized storm events are shown in Figure 9. These maps were obtained using Level 3, which is the retrieval protocol depicted in Figure 7. It is evident that the spatial variability for all rainfall types has been far better captured, especially for the case depicted in the second row of this figure. Since the optimized algorithm parameters resulting from the sensitivity

10 analysis have been used in these tests, the a priori initialization procedure heavily influences the algorithm output. It is apparent however that the algorithm smoothes the solution in all cases, as compared to the observed maps.

Local initialization has been shown to significantly improve retrieval algorithm performance. Yet, two critical questions arise: i) does this improvement stem solely from the a priori knowledge; and ii) does applying the inverse algorithm benefit rainfall retrieval. To answer these questions, we have compared the a priori knowledge with the inverse algorithm

15 performance at each step of the grid nesting procedure (Fig. 2) individually, meaning that the rainfall map values retrieved by the algorithm have been compared with the a priori rainfall map values introduced before the actual retrieval. This comparison was performed at each step of grid nesting. Figure 10 illustrates the results of the comparison using the NSE criterion, as plotted in efficiency curve. Let's note that the figures in the $1^{\text {st }}, 2^{\text {nd }}$ and $3^{\text {rd }}$ columns result from the $1^{\text {st }}, 2^{\text {nd }}$ and $3^{\text {rd }}$ steps of the grid nesting procedure, respectively. It is observed that the added value of the algorithm is highly significant at

$202 \times 2 \mathrm{~km}^{2}$, especially in the presence of strong rainfall variability, see for example the shower event. In other words, the greater the rainfall variability, the larger the influence of the inverse algorithm on output. This influence then moderates and becomes less significant at resolutions of $1 x 1 \mathrm{~km}^{2}$ and $0.5 x 0.5 \mathrm{~km}^{2}$, respectively. Interestingly, the overall contribution of the inverse algorithm becomes roughly the same as the retrieval resolution decreases from $2 x 2 \mathrm{~km}^{2}$ to $0.5 x 0.5 \mathrm{~km}^{2}$. This outcome is due to the fact that the a priori solutions in the $2^{\text {nd }}$ and $3^{\text {rd }}$ columns do not actually represent the local initialization. Instead, they are the results of the algorithm run during previous steps (i.e. steps 1 and 2 in the grid nesting procedure) and accepted as the a priori rainfall for the subsequent step.

Figure 11 displays the overall retrieval efficiency for the algorithm in NSE criterion vs. microwave link density. This plot is derived from the pixel density map. It is important to note that the line colors in Figure 11 are the same as those shown in Figure 4, except for the yellow color, which has been labeled as "whole density" (thus indicating an evaluation result without

30 the density map). It would seem that the algorithm accuracy within the denser part of the network, i.e. blue line, is quite high compared to the sparser part, i.e. the rainfall retrieved in the city center is more accurate than that in the suburban zone. Regions with a moderate density label (red line) however indicate an unusual performance in the first few retrieved maps. 
Hydrol. Earth Syst. Sci. Discuss., doi:10.5194/hess-2016-540, 2016

Manuscript under review for journal Hydrol. Earth Syst. Sci.

Published: 21 October 2016

(c) Author(s) 2016. CC-BY 3.0 License.

The explanation for such behavior is that the number of retrieved pixels to be compared with observed ones is much less than the pixels elsewhere, i.e. the red or blue regions.

The scatter plots of the retrieved rainfall shown in Figure 12 illustrate another perspective on the performance of the proposed algorithm. Regression lines in black and red colors have been placed on the observed maps (by weather radar) and on the estimated maps (by the algorithm), respectively. A systematic underestimation is observed across all events for both the whole and high density regions within the study area. However, this underestimation is decreasing in the denser regions of the network, as seen in the figures in the right-hand column. Note that higher rainfall rates are always being smoothed, thus resulting in an underestimation. This smoothing process is explained in two ways: i) the solution vector retrieved during the $1^{\text {st }}$ step of the grid nesting procedure essentially belongs to rural areas (moreover, it is not subsequently updated by the algorithm in the next steps); and ii) the longer microwave links are also causing an underestimation.

\section{Conclusion and Outlook}

\subsection{Conclusion}

The objective of this study has been to assess the feasibility of rainfall mapping by means of an inverse method applied to signal attenuation data generated on an existing microwave link network within a simulation framework. The new retrieval

15 algorithm based on the inverse method has been proposed to demonstrate the capability of microwave links for rainfall monitoring in urban areas. We have demonstrated that the a priori knowledge used to initialize the algorithm heavily influences retrieval accuracy even when rainfall variability is high. A detailed sensitivity analysis focusing on the $a$ priori parameters has also been performed to test algorithm stability at different levels of rainfall variability. The algorithm applied has been found stable enough even if the problem to be solved remains overly under-determined, as found to be the case

20 herein. Various evaluation procedures have been carried out to analyze monitoring system performance. One weakness of the algorithm identified during the evaluation process is its systematic underestimation, especially with very high rainfall intensity. However, the proposed algorithm is still suitable with larger-magnitude measurement errors.

\subsection{Future work}

This research study opens several new avenues of future study to better understand the rainfall retrieval capability of commercial microwave links.

Further work could be dedicated to assessing the long-term effects of the cellular network used for rainfall monitoring based on a more extensive dataset, e.g. one week of instantaneous rainfall provided by weather radar. In addition, the structure used to model uncertainty introduced into the algorithm could be changed based on the same recommendation given in the previous section, in order to provide a deeper understanding of algorithm capabilities as well as limitations. Since this

30 retrieval algorithm relies heavily on a priori knowledge, different types of a priori initialization procedures can as an option be introduced to raise the degree of accuracy in the output. 
Hydrol. Earth Syst. Sci. Discuss., doi:10.5194/hess-2016-540, 2016

As regards the simulation framework adopted for this work, further research is required to improve the quality of the resulting rain attenuation data in order to reflect a real type of signal data capable of being measured at microwave antenna stations. Moreover, the error magnitude, i.e. standard deviation, introduced in the algorithm does not take modeling errors into account. This shortcoming may be remedied however by devising a new structure that includes link characteristics (essentially frequency and length) and climate conditions, such as temperature, humidity, gas and water vapor effects. Such an error structure could be developed on the basis of the methodology for modeling error sources and uncertainty proposed by (Zinevich, et al., 2010).

Furthermore, it would be interesting to test these two proposed retrieval algorithms in different cities throughout the world based on an actual case study that requires signal attenuation data obtained directly from cellular phone companies. This idea

10 however will naturally raise the challenge of having to cleanse the signal data recorded at antenna stations before use in rainfall retrieval. Signal attenuation unrelated to rainfall includes baseline effects (i.e. gas, water vapor, temperature, wind) and antenna wetting following the rainy period. The algorithms developed by (Upton, et al., 2005; Schleiss \& Berne, 2010; Fenicia, et al., 2012) are available for removing these effects from the actual signal data. Retrieval algorithms developed by (Giuli, et al., 1999; Zinevich, et al., 2008; Goldshtein, et al., 2009; Overeem, et al., 2013) can also be compared with the

15 algorithm proposed in this work in the presence of various modeling and measurement error sources (Leijnse, et al., 2010) using either generated or real signal attenuation data obtained by mobile phone companies.

A global perspective on the main objective of this research might entail combining the commercial microwave links with weather radar in order to improve the accuracy of real-time rainfall monitoring within urban areas.

\section{Acknowledgments}

20 This research work was funded by the European Union (Erasmus Mundus organization, ARCADE project, Action II). The authors would like to thank Mr. Agnani with France's National Frequency Agency for providing the microwave link network antenna positions used in this study; warm thanks are also addressed to our colleague Dr. Emmanuel, who compiled the rainfall dataset recorded by weather radar at the French Meteorological Office. In addition, our deepest gratitude is expressed to Professors C. Mallet and J.P. Guédon for their useful suggestions throughout this project.

\section{References}

1. Atlas, D. \& Ulbrich, C. W., 1977. Path-and area-integrated rainfall measurement by microwave attenuation in the 1$3 \mathrm{~cm}$ band. Journal of Applied Meteorology, 16(12), pp. 1322-1331.

2. Berne, A. \& Uijlenhoet, R., 2007. Path-averaged rainfall estimation using microwave links: Uncertainty due to spatial rainfall variability. Geophysical research letters, 34(7). 
Hydrol. Earth Syst. Sci. Discuss., doi:10.5194/hess-2016-540, 2016

Manuscript under review for journal Hydrol. Earth Syst. Sci.

Published: 21 October 2016

(c) Author(s) 2016. CC-BY 3.0 License.

3. Bianchi, B., Rieckermann, J. \& Berne, A., 2013. Quality control of rain gauge measurements using telecommunication microwave links. Journal of Hydrology, Volume 492, pp. 15-23.

4. Creutin, J. \& Obled, C., 1982. Objective analyses and mapping techniques for rainfall fields: an objective comparison. Water resources research, 18(2), pp. 413-431.

5. Cuccoli, F., Facheris, L., Gori, S. \& Baldini, L., 2011. Retrieving rainfall fields through tomographic processing applied to radio base network signals. s.1., s.n., pp. 81740C--81740C.

6. Cummings, R., Upton, G. J., Holt, A. \& Kitchen, M., 2009. Using microwave links to adjust the radar rainfall field. Advances in water resources, 32(7), pp. 1003-1010.

7. Doumounia, A. et al., 2014. Rainfall monitoring based on microwave links from cellular telecommunication networks: First results from a West African test bed. Geophysical Research Letters, 41(16), pp. 6016-6022.

8. Emmanuel, I., Andrieu, H., Leblois, E. \& Flahaut, B., 2012. Temporal and spatial variability of rainfall at the urban hydrological scale. Journal of hydrology, Volume 430, pp. 162-172.

9. Fenicia, F. et al., 2012. Microwave links for rainfall estimation in an urban environment: Insights from an experimental setup in Luxembourg-City. Journal of Hydrology, Volume 464, pp. 69-78.

10. Giuli, D., Facheris, L. \& Tanelli, S., 1999. Microwave tomographic inversion technique based on stochastic approach for rainfall fields monitoring. Geoscience and Remote Sensing, IEEE Transactions on, 37(5), pp. 25362555 .

11. Giuli, D., Toccafondi, A., Gentili, G. B. \& Freni, A., 1991. Tomographic reconstruction of rainfall fields through microwave attenuation measurements. Journal of Applied Meteorology, 30(9), pp. 1323-1340.

12. Goldshtein, O., Messer, H. \& Zinevich, A., 2009. Rain rate estimation using measurements from commercial telecommunications links. Signal Processing, IEEE Transactions on, 57(4), pp. 1616-1625.

13. Gosset, M. et al., 2015. Improving Rainfall Measurement in gauge poor regions thanks to mobile telecommunication networks.. Bulletin of the American Meteorological Society, Issue 2015.

14. Hogg, D. C., 1968. Millimeter-Wave Communication through the Atmosphere. Science, 159(3810), pp. 39-46.

15. ITU-R, U., 2005. 838-3. Specific attenuation model for rain for use in prediction methods. Intern. Telecom. Union, Geneva.

16. Kak, A. C. \& Slaney, M., 1988. Principles of Computerized Tomographic Imaging. s.1.:SIAM.

17. Leijnse, H., Uijlenhoet, R. \& Berne, A., 2010. Errors and uncertainties in microwave link rainfall estimation explored using drop size measurements and high-resolution radar data. Journal of Hydrometeorology, 11(6), pp. 1330-1344.

18. Leijnse, H., Uijlenhoet, R. \& Stricker, J., 2007. Hydrometeorological application of a microwave link: 2. Precipitation. Water resources research, 43(4).

19. Leijnse, H., Uijlenhoet, R. \& Stricker, J., 2007. Rainfall measurement using radio links from cellular communication networks. Water resources research, 43(3). 
Hydrol. Earth Syst. Sci. Discuss., doi:10.5194/hess-2016-540, 2016

Manuscript under review for journal Hydrol. Earth Syst. Sci.

Published: 21 October 2016

(c) Author(s) 2016. CC-BY 3.0 License.
Hydrology and

Earth System

Sciences

Discussions

(c) (i)

20. Leijnse, H., Uijlenhoet, R. \& Stricker, J. N. M., 2008. Microwave link rainfall estimation: Effects of link length and frequency, temporal sampling, power resolution, and wet antenna attenuation. Adv. $\backslash$ Water Resour., 31(11), pp. 1481-1493.

21. Menke, W., 1989. Geophysical Data Analysis: Discrete Inverse Theory. s.l.:Elsevier Science.

22. Messer, H., Zinevich, A. \& Alpert, P., 2006. Environmental monitoring by wireless communication networks. Science, 312(5774), pp. 713-713.

23. Nash, J. E. \& Sutcliffe, J. V., 1970. River flow forecasting through conceptual models part I-A discussion of principles. Journal of hydrology, 10(3), pp. 282-290.

24. Olsen, R. L., Rogers, D. V. \& Hodge, D. B., 1978. The aR b relation in the calculation of rain attenuation. Antennas and Propagation, IEEE Transactions on, 26(2), pp. 318-329.

25. Ostrometzky, J., Cherkassky, D. \& Messer, H., 2015. Accumulated Mixed Precipitation Estimation Using Measurements from Multiple Microwave Links. Advances in Meteorology, Volume 2015.

26. Overeem, A., Leijnse, H. \& Uijlenhoet, R., 2011. Measuring urban rainfall using microwave links from commercial cellular communication networks. Water Resources Research, 47(12).

27. Overeem, A., Leijnse, H. \& Uijlenhoet, R., 2013. Country-wide rainfall maps from cellular communication networks. Proceedings of the National Academy of Sciences, 110(8), pp. 2741-2745.

28. Rahimi, A. et al., 2006. Attenuation calibration of an X-band weather radar using a microwave link. Journal of Atmospheric and Oceanic Technology, 23(3), pp. 395-405.

29. Rayitsfeld, A. et al., 2012. Comparison of two methodologies for long term rainfall monitoring using a commercial microwave communication system. Atmospheric Research, Volume 104, pp. 119-127.

30. Schleiss, M. \& Berne, A., 2010. Identification of Dry and Rainy Periods Using Telecommunication Microwave Links. IEEE Geoscience and Remote Sensing Letters, July, 7(3), pp. 611-615.

31. Shepard, D., 1968. A two-dimensional interpolation function for irregularly-spaced data. s.1., s.n., pp. 517-524.

32. Tarantola, A., 2005. Inverse problem theory and methods for model parameter estimation. s.1.:siam.

33. Tarantola, A. \& Valette, B., 1982a. Generalized nonlinear inverse problems solved using the least squares criterion. Rev. Geophys. Space Phys, 20(2), pp. 219-232.

34. Tarentola, A., 1987. Inverse Problem Theory: Methods for data fitting and model parameters estimation. E lse v ier.

35. Upton, G. et al., 2005. Microwave links: The future for urban rainfall measurement?. Atmospheric research, 77(1), pp. 300-312.

36. Welch, G. \& Bishop, G., 2006. An introduction to the kalman filter. Department of Computer Science, University of North Carolina. s.l.:Chapel Hill, NC, unpublished manuscript.

37. Widrow, B. \& Kollàr, I., 2008. Quantization Noise: Cambridge, UK: Cambridge University Press.

38. Zinevich, A., Alpert, P. \& Messer, H., 2008. Estimation of rainfall fields using commercial microwave communication networks of variable density. Advances in water resources, 31(11), pp. 1470-1480. 
Hydrol. Earth Syst. Sci. Discuss., doi:10.5194/hess-2016-540, 2016

Manuscript under review for journal Hydrol. Earth Syst. Sci.

Published: 21 October 2016

(c) Author(s) 2016. CC-BY 3.0 License.

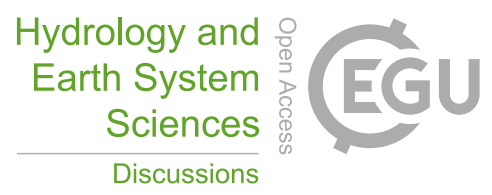

(c) (i)

39. Zinevich, A., Messer, H. \& Alpert, P., 2009. Frontal rainfall observation by a commercial microwave communication network. Journal of Applied Meteorology and Climatology, 48(7), pp. 1317-1334.

40. Zinevich, A., Messer, H. \& Alpert, P., 2010. Prediction of rainfall intensity measurement errors using commercial microwave communication links. Atmospheric Measurement Techniques, 3(5), pp. 1385-1402. 
Hydrol. Earth Syst. Sci. Discuss., doi:10.5194/hess-2016-540, 2016

Manuscript under review for journal Hydrol. Earth Syst. Sci.

Published: 21 October 2016

(c) Author(s) 2016. CC-BY 3.0 License.
Hydrology and o

Earth System

Sciences

Discussions

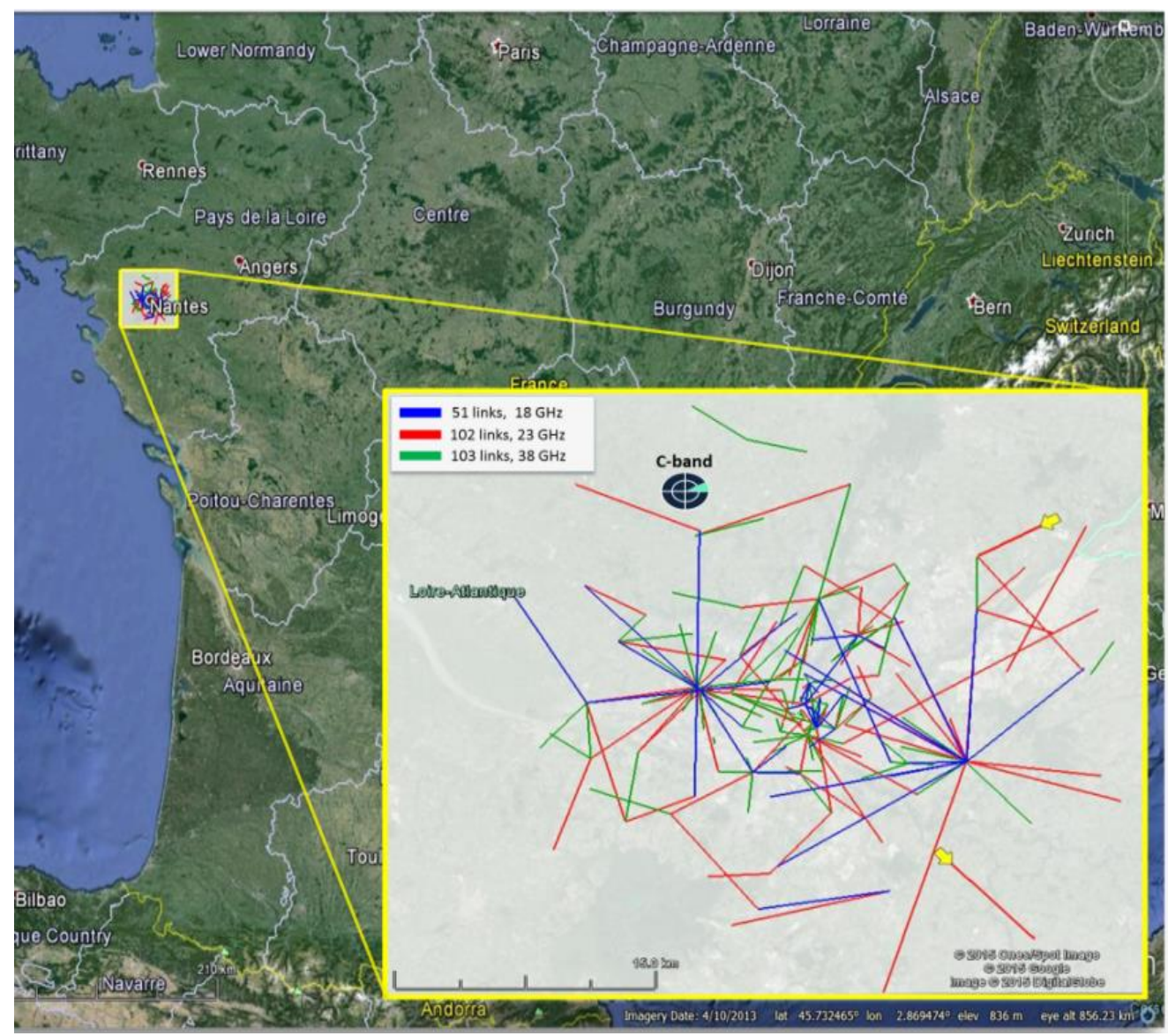

Figure 1. Mobile phone network located in Nantes city. The zoomed-in part of the figure (yellow square) represents the location of microwave link antennas (Transmitter and Receiver stations) operating at 18, 23 and 38 GHz. Two yellow arrows are also depicted as an example to indicate transmitter stations. 
Hydrol. Earth Syst. Sci. Discuss., doi:10.5194/hess-2016-540, 2016

Manuscript under review for journal Hydrol. Earth Syst. Sci.

Published: 21 October 2016

(c) Author(s) 2016. CC-BY 3.0 License.

Apriori rain

Stage 1

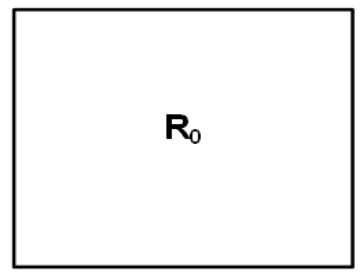

Stage 2

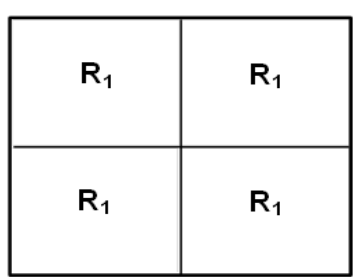

Stage 3

\begin{tabular}{|l|l|l|l|}
\hline $\mathbf{R}_{3}$ & $\mathbf{R}_{3}$ & $\mathbf{R}_{\mathbf{4}}$ & $\mathbf{R}_{\mathbf{4}}$ \\
\hline $\mathbf{R}_{3}$ & $\mathbf{R}_{3}$ & $\mathbf{R}_{\mathbf{4}}$ & $\mathbf{R}_{\mathbf{4}}$ \\
\hline $\mathbf{R}_{\mathbf{1}}$ & $\mathbf{R}_{\mathbf{1}}$ & $\mathbf{R}_{2}$ & $\mathbf{R}_{\mathbf{2}}$ \\
\hline $\mathbf{R}_{\mathbf{1}}$ & $\mathbf{R}_{\mathbf{1}}$ & $\mathbf{R}_{2}$ & $\mathbf{R}_{2}$ \\
\hline
\end{tabular}

Solution vector
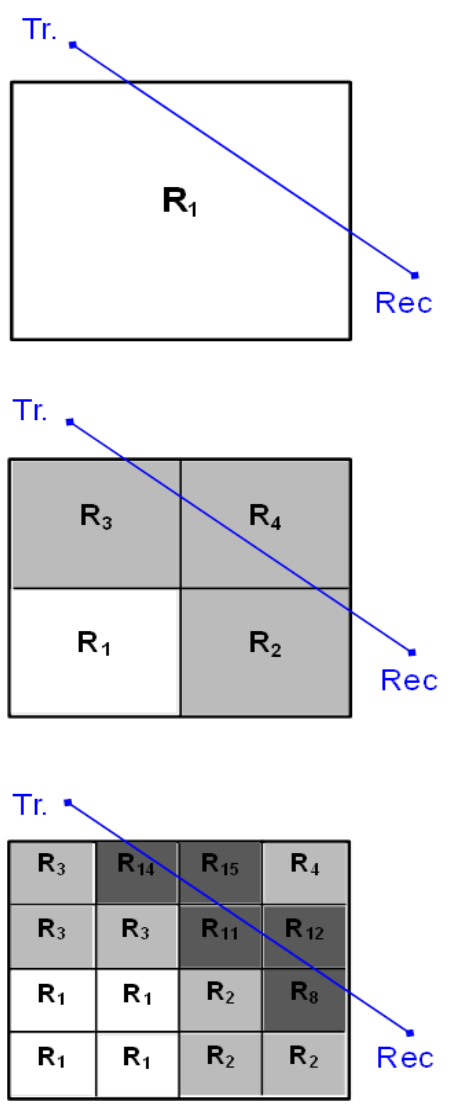

Figure 2: Grid nesting procedure applied to one pixel crossed by a link. The left and the right columns represent the a priori and retrieved rainfall by the algorithm, respectively. The rows (top-down direction) are the stage 1, 2 and 3 in grid nesting procedure.

$R$ stands for rain rate value. The segment line (in blue) is a sample microwave link and its labels, 'Tr.' and 'Rec.', stand for Transmitter and Receiver, respectively. 
Hydrol. Earth Syst. Sci. Discuss., doi:10.5194/hess-2016-540, 2016

Manuscript under review for journal Hydrol. Earth Syst. Sci.

Published: 21 October 2016

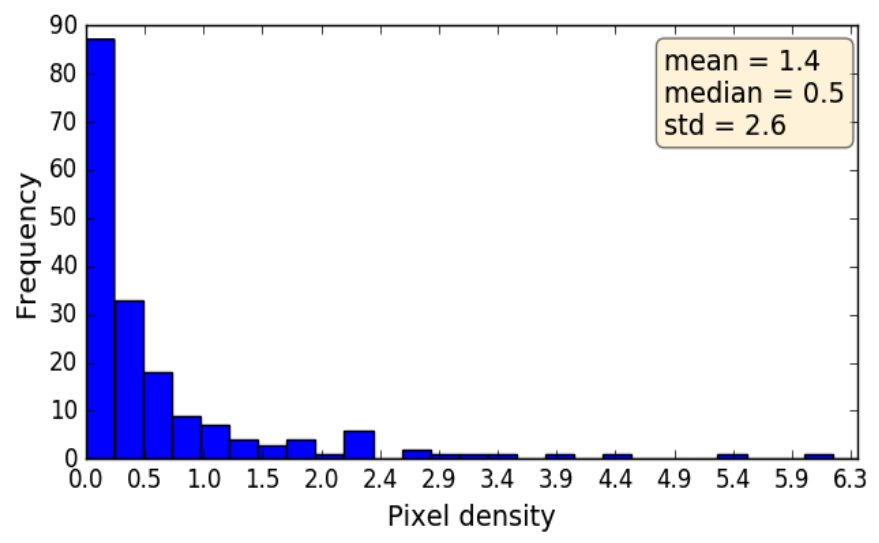

Figure 3. Histogram of the pixel density map values.

10

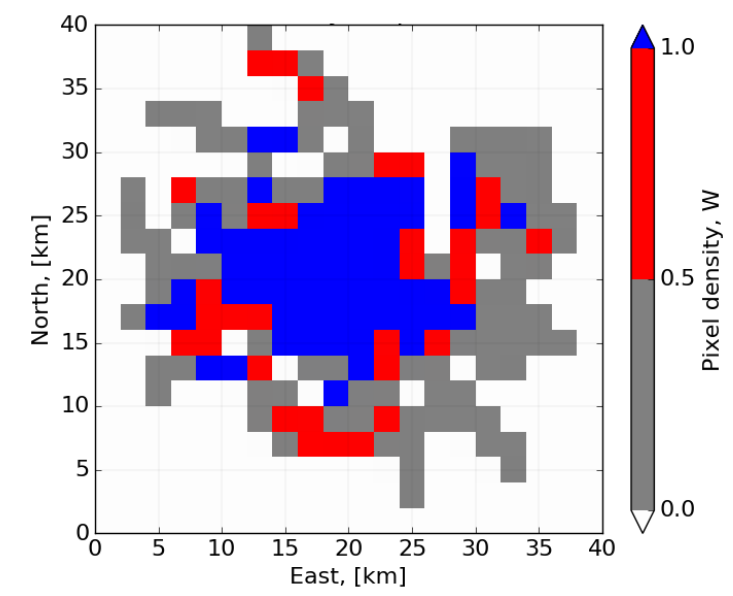

Figure 4. Pixel density map computed over the microwave link area. 
Hydrol. Earth Syst. Sci. Discuss., doi:10.5194/hess-2016-540, 2016

Manuscript under review for journal Hydrol. Earth Syst. Sci.

Published: 21 October 2016

(c) Author(s) 2016. CC-BY 3.0 License.
Hydrology and

Earth System

Sciences

Discussions

(c) $\underset{\mathrm{By}}{\mathrm{B}}$

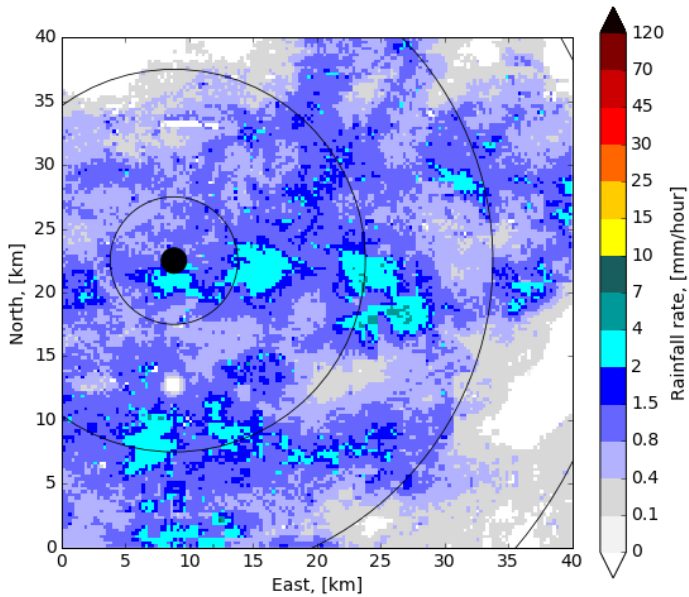

(a) Light rain, 17/09/2009 at 00h30

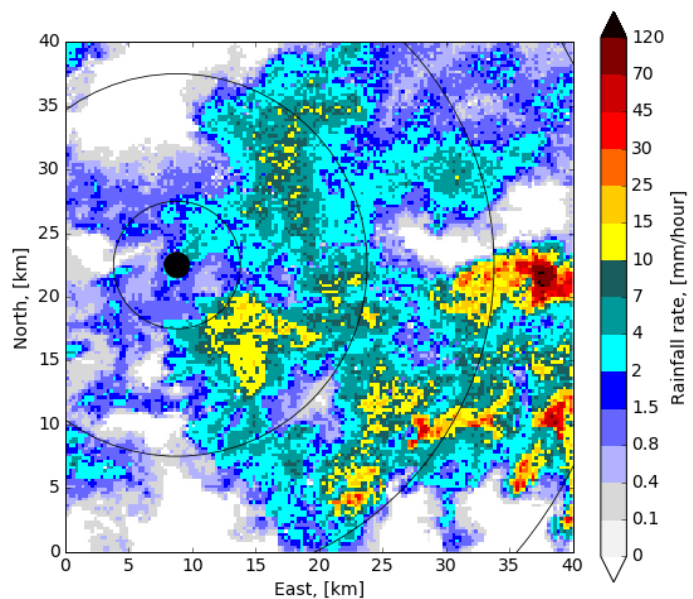

(c) Organized storm, 11/06/2012 at $13 \mathrm{~h} 00$

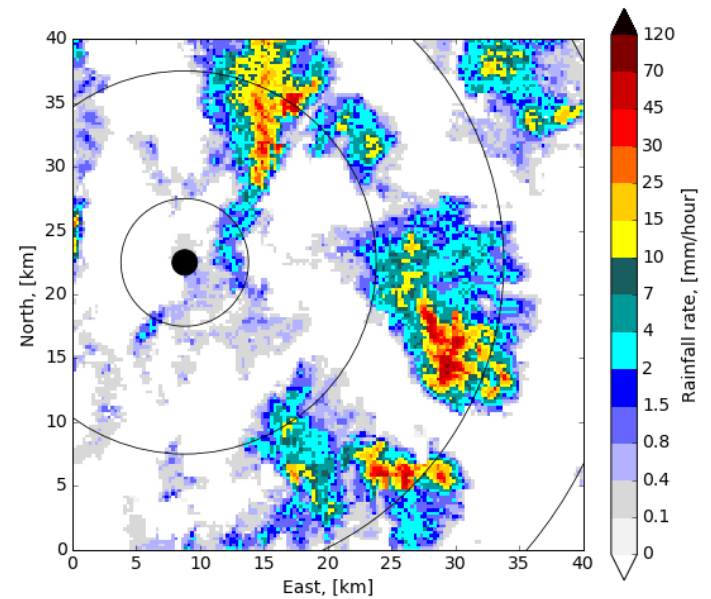

(b) Shower, 04/07/2012 at 12h50

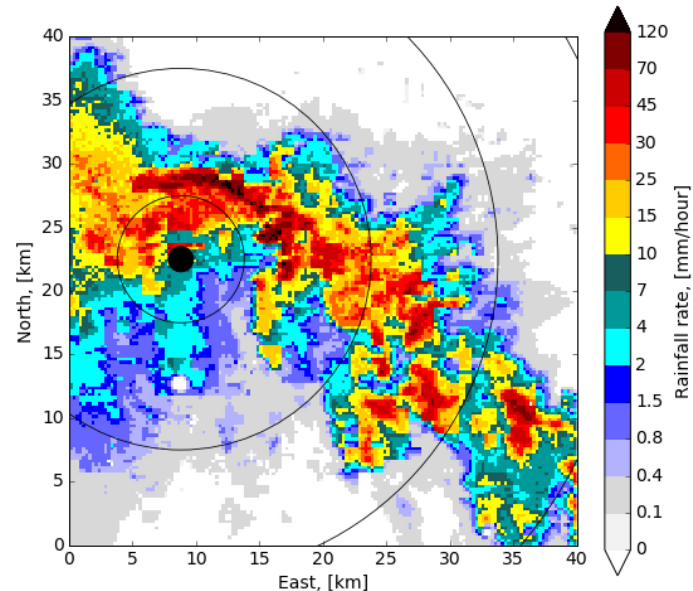

(d) Unorganized storm, $25 / 05 / 2009$ at $00 \mathrm{~h} 25$

Figure 5. Example of weather radar rainfall maps recorded at spatial ( $250 \mathrm{~m} \times 250 \mathrm{~m})$ and temporal (5 min.) resolutions. 
Hydrol. Earth Syst. Sci. Discuss., doi:10.5194/hess-2016-540, 2016

Manuscript under review for journal Hydrol. Earth Syst. Sci.

Published: 21 October 2016

(c) Author(s) 2016. CC-BY 3.0 License.

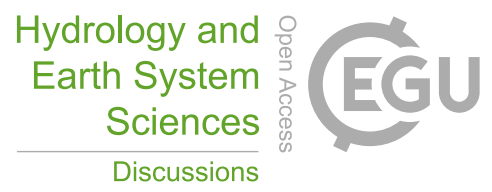

(c) (1)
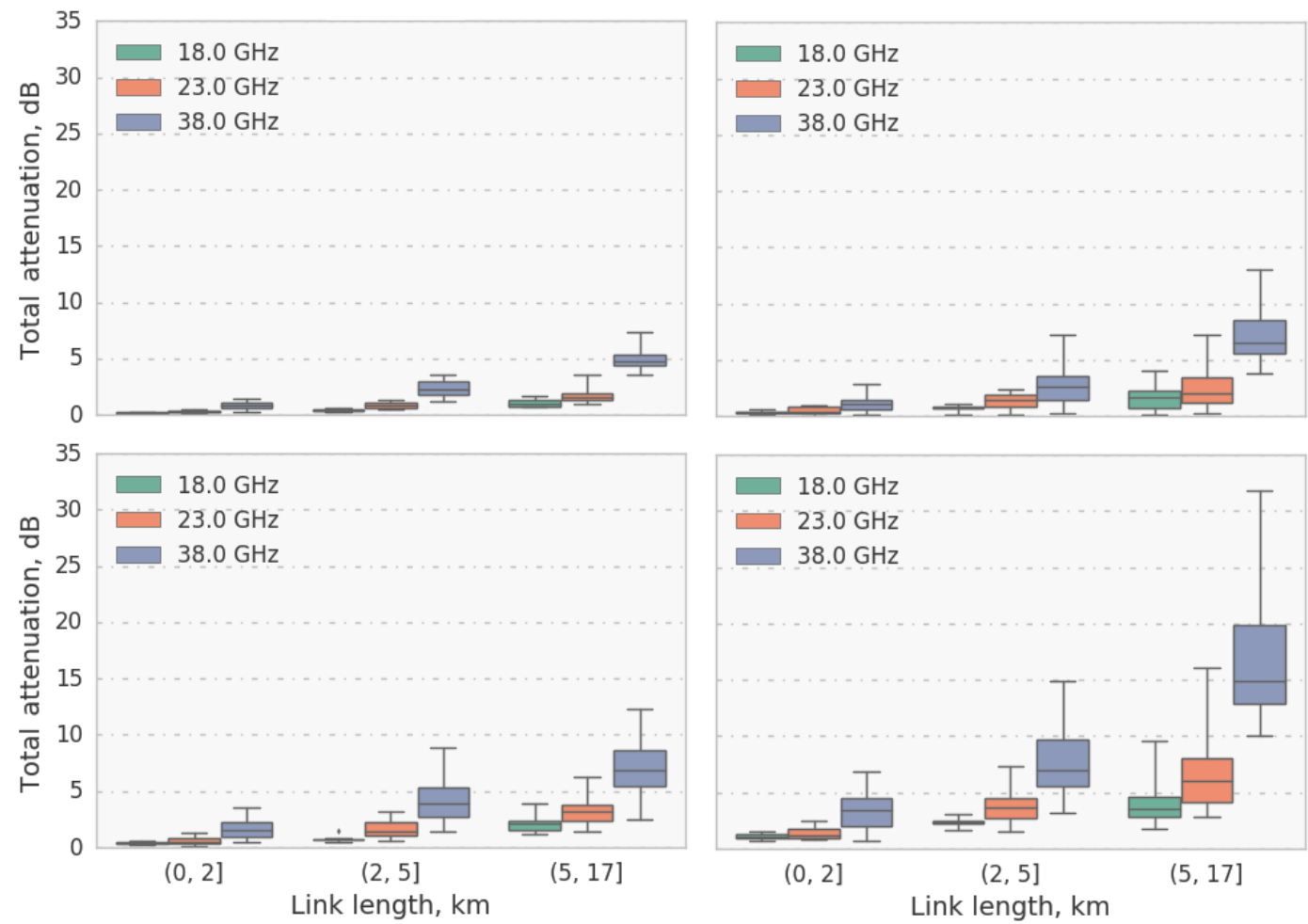

Figure 6. Boxplot of overall generated PIA data set. Note that $y$ axis represents the mean values of path integrated attenuation. 5 The figures (clock-wise direction) represent light rain, shower, unorganized and organized storm events. 
Hydrol. Earth Syst. Sci. Discuss., doi:10.5194/hess-2016-540, 2016

Manuscript under review for journal Hydrol. Earth Syst. Sci.

(c) Author(s) 2016. CC-BY 3.0 License.

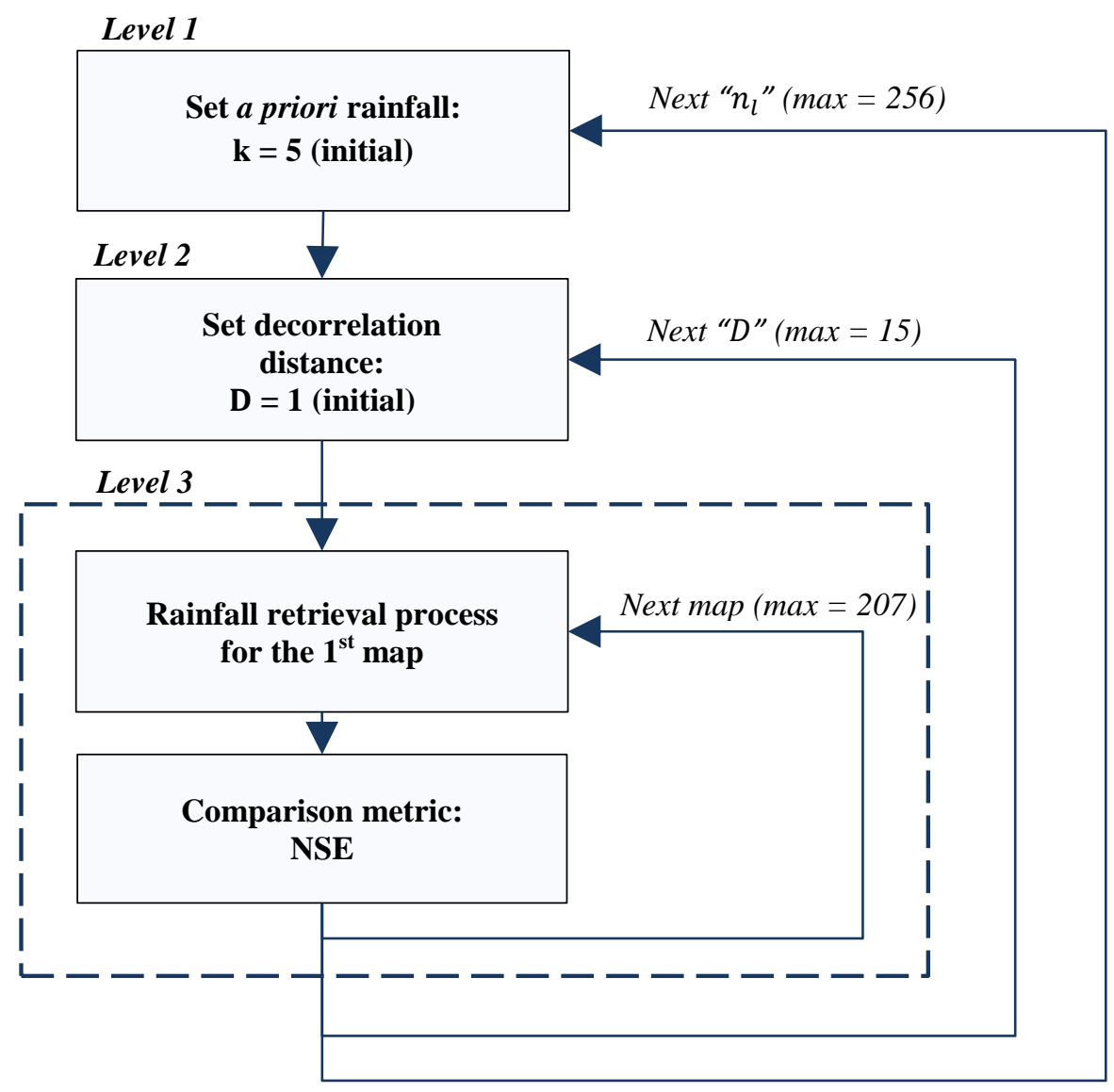

Figure 7. Overall structure of the sensitivity analysis test. 
Hydrol. Earth Syst. Sci. Discuss., doi:10.5194/hess-2016-540, 2016

Manuscript under review for journal Hydrol. Earth Syst. Sci.

Published: 21 October 2016

(c) Author(s) 2016. CC-BY 3.0 License.
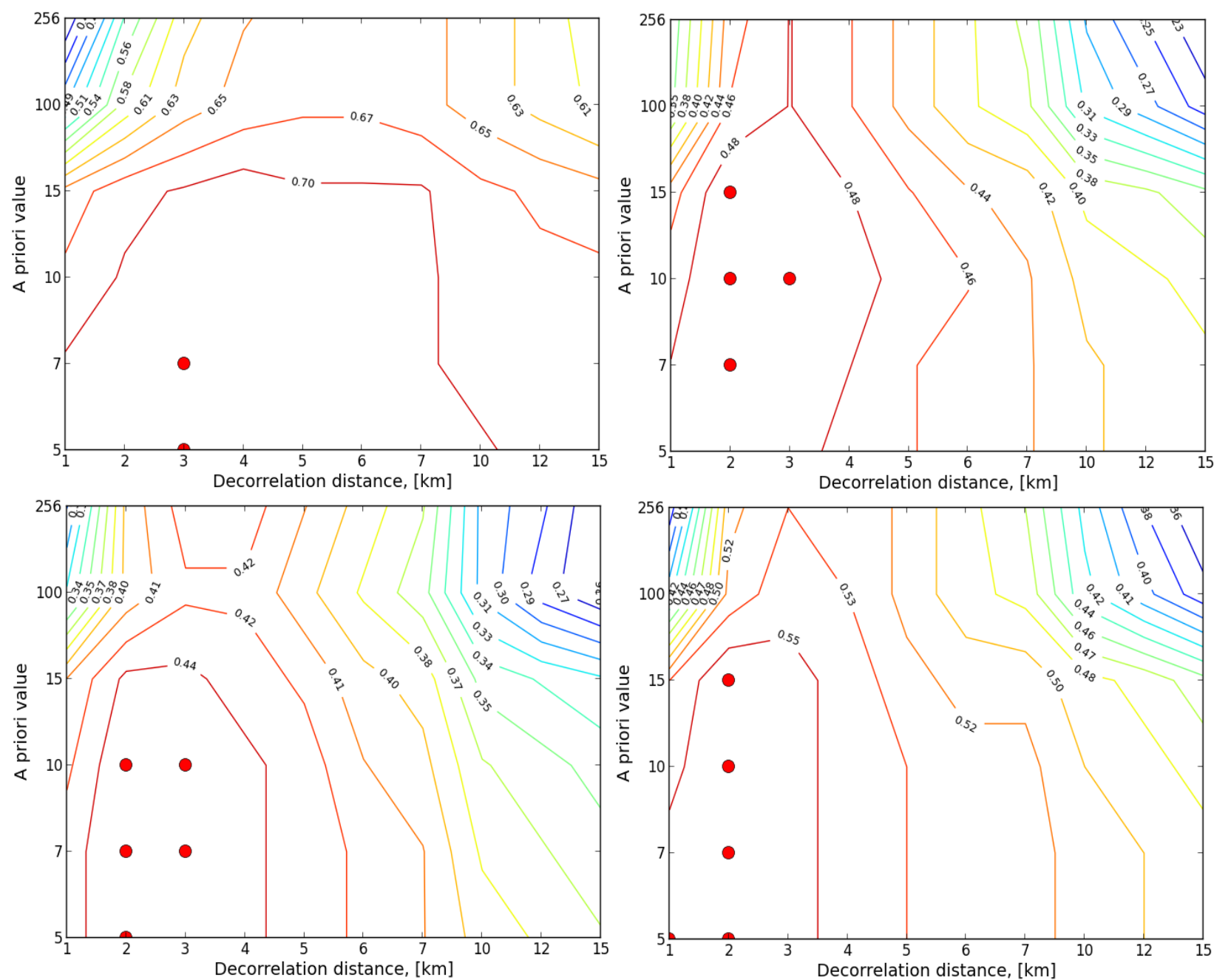

Figure 8. Influence of the a priori parameters on the efficiency of the algorithm in NSE criterion for light rain, shower, unorganized and organized storm events (clock-wise direction). The red dots in the figure indicate the location of the optimal parameters of both a priori and decorrelation distance. Note that, the NSE values are averaged over all maps in each event. 
Hydrol. Earth Syst. Sci. Discuss., doi:10.5194/hess-2016-540, 2016

Manuscript under review for journal Hydrol. Earth Syst. Sci.

Published: 21 October 2016

(c) Author(s) 2016. CC-BY 3.0 License.
Hydrology and

Earth System

Sciences

Discussions
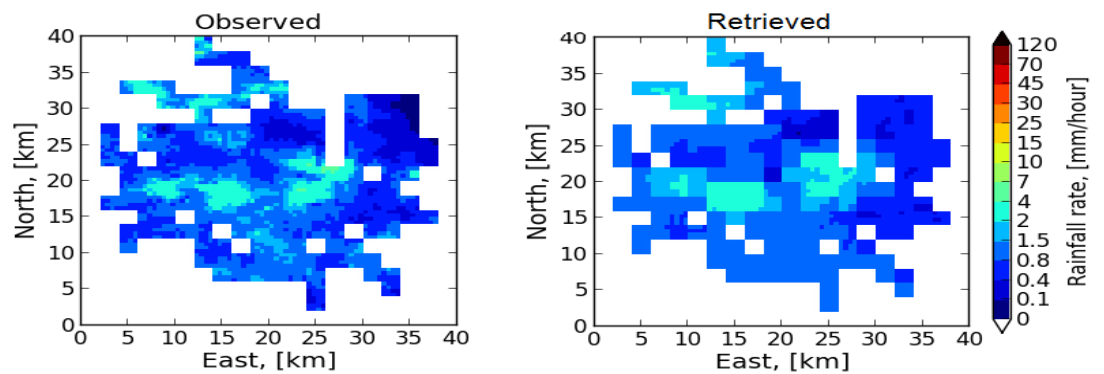

(a) Light rain, Time: 00h30, 17.09.2009
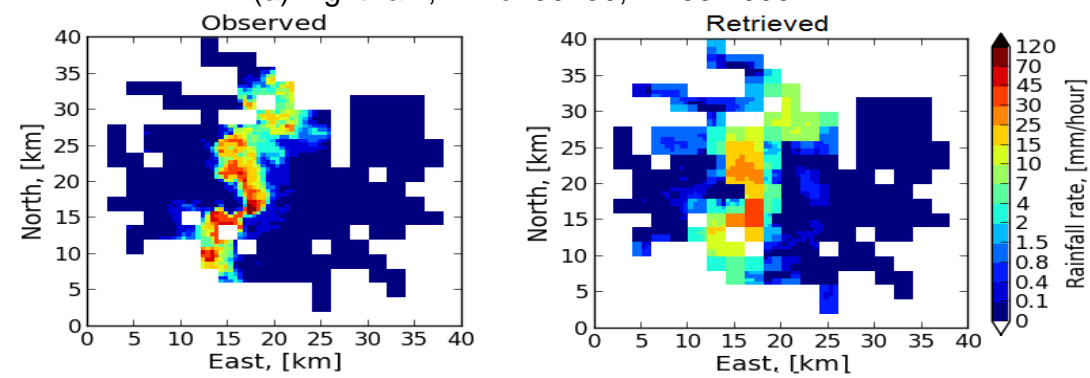

(b) Shower, Time: 20h45, 20.06.2012
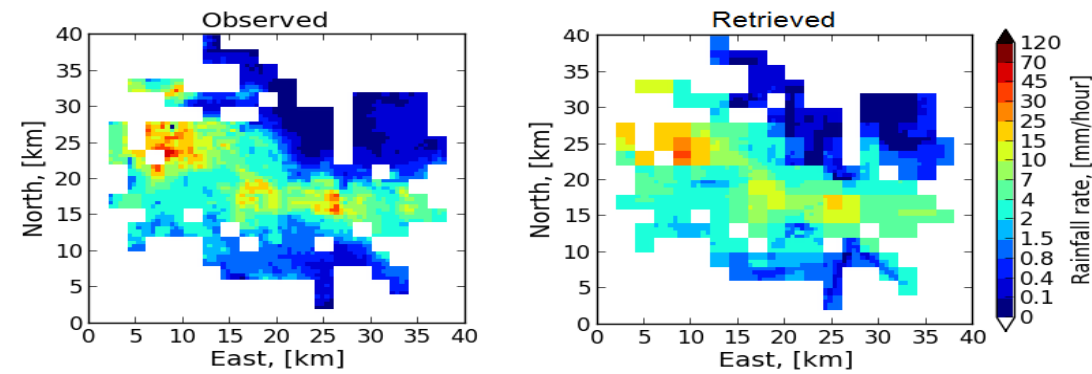

(c) Organized storm, Time: 05h25, 07.06.2012
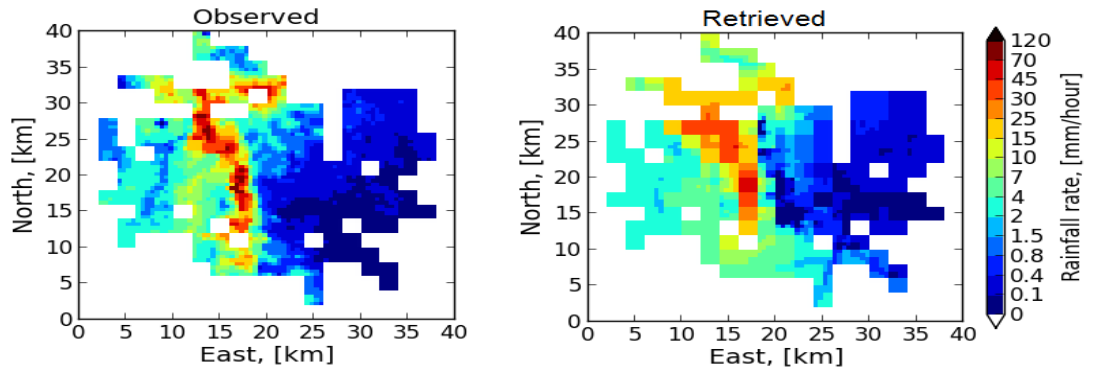

(d) Unorganized storm, Time: 18h10, 11.05.2009

Figure 9. Example of rainfall maps retrieved in different events: (a) light rain, (b) shower, (c) organized and (d) unorganized storm. The figures on the left and right represent rainfall maps observed by weather radar (ground-truth) and retrieved by the proposed algorithm, respectively. 
Hydrol. Earth Syst. Sci. Discuss., doi:10.5194/hess-2016-540, 2016

Manuscript under review for journal Hydrol. Earth Syst. Sci.

Published: 21 October 2016

(c) Author(s) 2016. CC-BY 3.0 License.

(c) (i)
Hydrology and
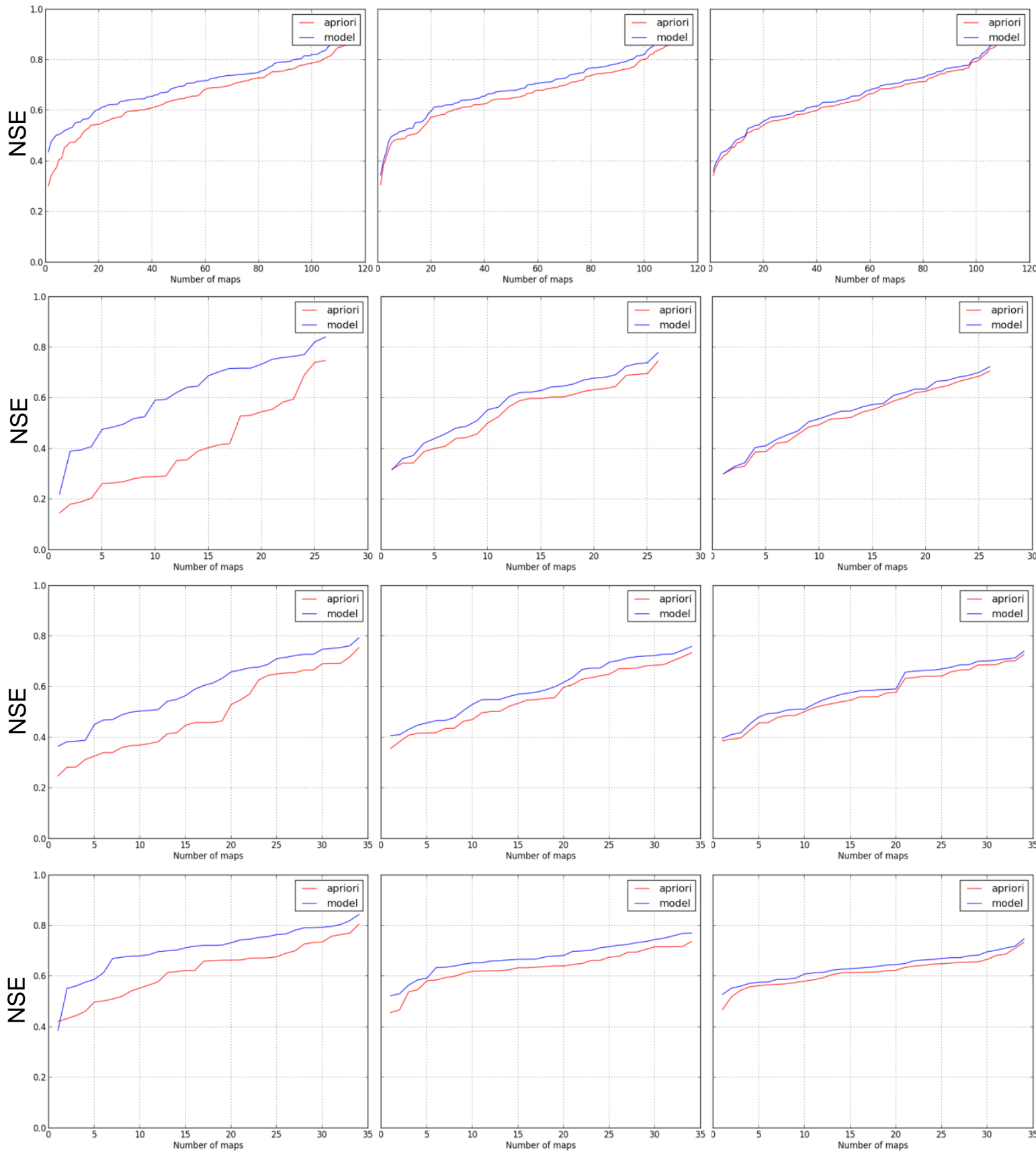

Figure 10. Comparison between inverse model and a priori knowledge at $2 \times 2 \mathrm{~km}^{2}, 1 \times 1 \mathrm{~km}^{2}$ and $0.5 \times 0.5 \mathrm{~km}^{2}$ resolutions which belong to 1st, 2nd and 3rd columns, respectively. Red solid lines indicate the NSE values using only a priori knowledge before applying the inverse algorithm. Blue solid lines indicate the NSE values obtained after applying the inverse algorithm. Rows (top down direction) represent light rain, shower, organized and unorganized storm events. 
Hydrol. Earth Syst. Sci. Discuss., doi:10.5194/hess-2016-540, 2016

Manuscript under review for journal Hydrol. Earth Syst. Sci.

Published: 21 October 2016

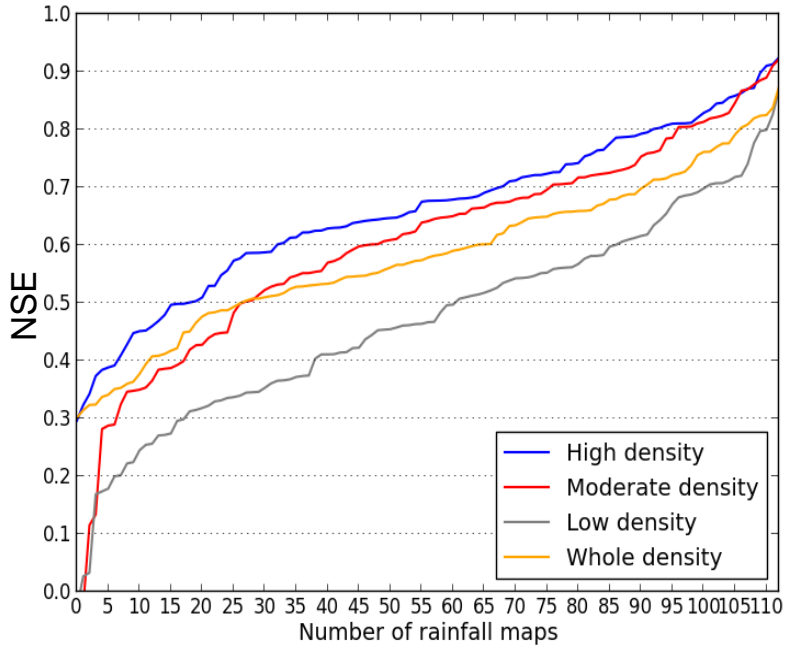

(a) Light rain event

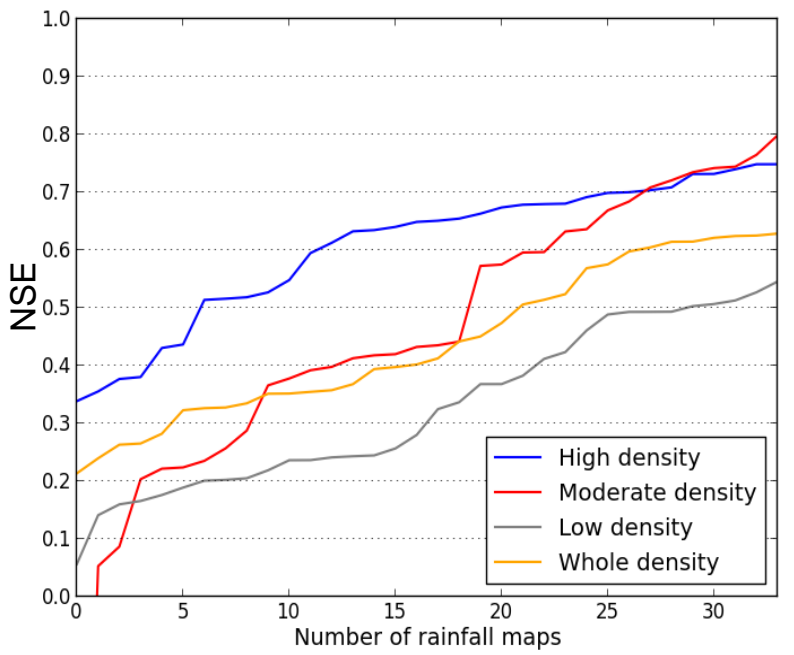

(c) Organized storm event

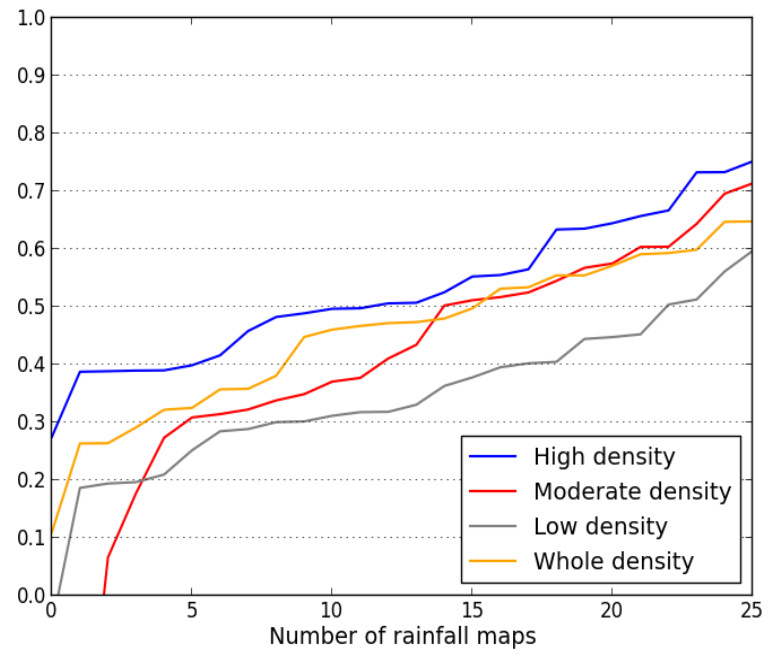

(b) Shower event

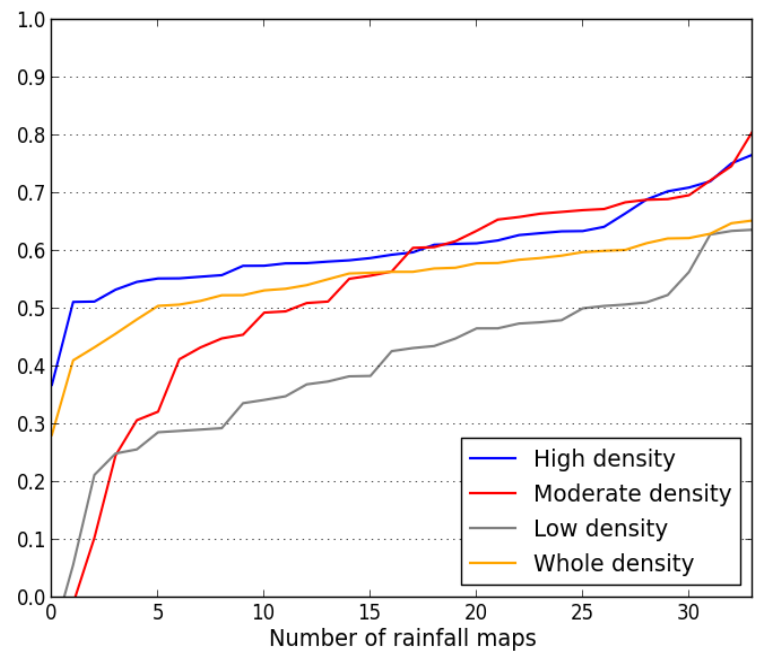

(d) Unorganized storm event

Figure 11. The retrieval efficiency in NSE at $0.5 \times 0.5 \mathrm{~km}^{2}$ resolution in different parts of the monitoring area classified as high, moderate, low and whole density. The evaluation test is in the presence of magnitude of measurement and model $(\alpha=5 \%)$ and quantization $(0.1 \mathrm{~dB})$ errors. The figures in the clock-wise direction represent light rain, shower, unorganized and organized storm. Note that map numbers in $\mathrm{x}$ axis are ordered to illustrate NSE values in ascending order. 
Hydrol. Earth Syst. Sci. Discuss., doi:10.5194/hess-2016-540, 2016 Manuscript under review for journal Hydrol. Earth Syst. Sci.

Published: 21 October 2016

(c) Author(s) 2016. CC-BY 3.0 License.
Hydrology and

(c) $\underset{\mathrm{BY}}{(i)}$
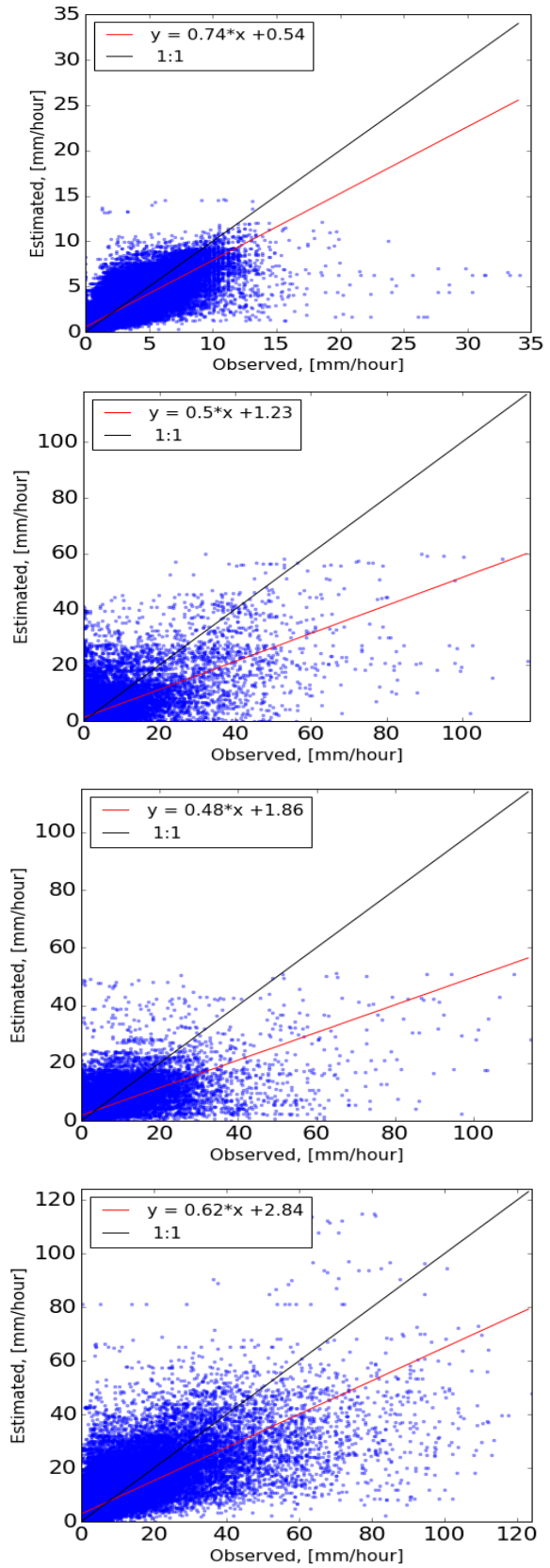
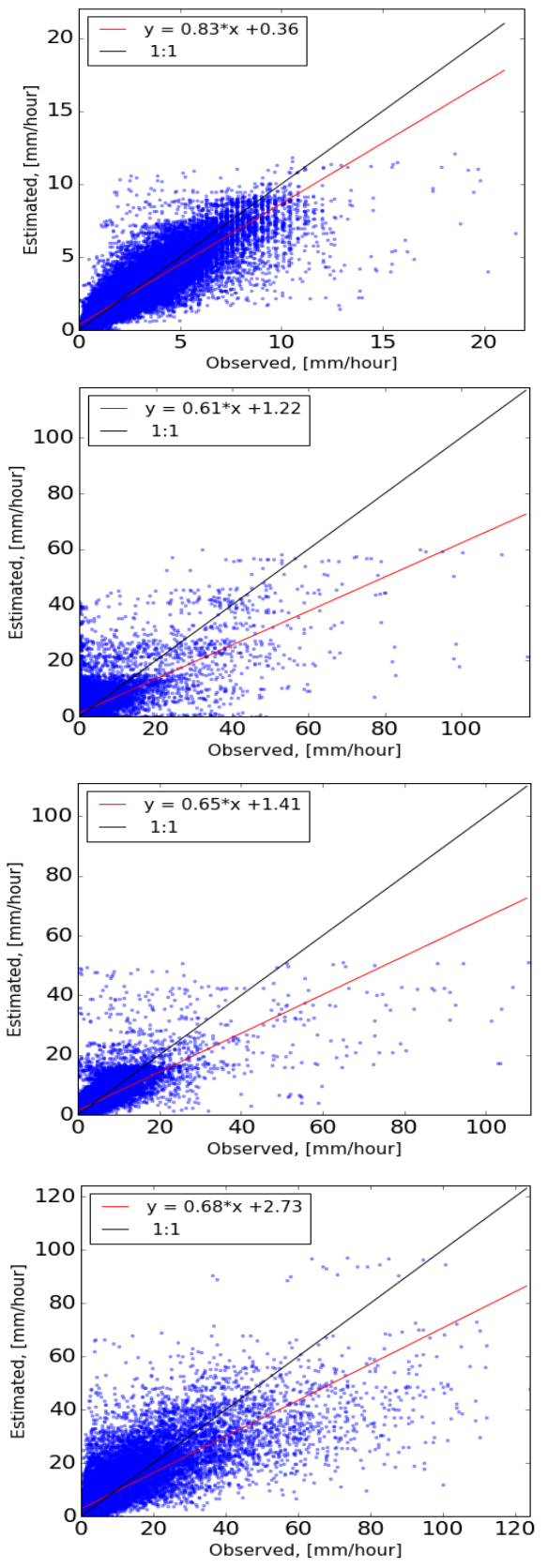

Figure 12. Scatter plot and fitted linear regression line (red) in 4 rain events: light rain, shower, organized and unorganized storm (top-down direction). The retrieved rainfall maps were obtained in the presence of the measurement and model (5 \%), 5 quantization $(0.1 \mathrm{~dB})$. Right and left hand side of the figure show the scatterplots computed for whole and high density regions of the study area. Note that the linear fit has been calculated over the whole dataset for each event at $0.5 \times 0.5 \mathrm{~km}^{2}$ resolution. 
Hydrol. Earth Syst. Sci. Discuss., doi:10.5194/hess-2016-540, 2016

Manuscript under review for journal Hydrol. Earth Syst. Sci.

Published: 21 October 2016

(c) Author(s) 2016. CC-BY 3.0 License.

\begin{tabular}{lcccc}
\hline & $18 \mathrm{GHz}$ & $23 \mathrm{GHz}$ & $38 \mathrm{GHz}$ & Total \\
\hline Number & 51 & 102 & 103 & 256 \\
Mean length $(\mathrm{km})$ & 5.3 & 5.2 & 2.6 & 4.2 \\
Min. length $(\mathrm{km})$ & 0.8 & 0.5 & 0.3 & 0.3 \\
Max. length $(\mathrm{km})$ & 12.6 & 16.8 & 9.1 & 16.8 \\
\hline
\end{tabular}

Table 1. Statistical description of the microwave links length.

\begin{tabular}{lccc}
\hline Event type & Duration & $\begin{array}{c}\text { Number } \\
\text { of fields }\end{array}$ & Period \\
\hline Light rain & $03 \mathrm{~h} 05$ & 37 & Sep-2009 \\
Light rain & $06 \mathrm{~h} 20$ & 76 & Jun-2012 \\
Shower & $01 \mathrm{~h} 30$ & 18 & Jun-2012 \\
Shower & $40 \mathrm{~min}$ & 8 & Jul-2012 \\
Organized & $02 \mathrm{~h} 50$ & 34 & Jun-2012 \\
Unorganized storm & $45 \mathrm{~min}$ & 19 & May-2009 \\
Unorganized storm & $75 \mathrm{~min}$ & 15 & Jun-2009 \\
\hline
\end{tabular}

Table 2. Rainfall event periods selected for the case study.

10

\begin{tabular}{lllll}
\hline & Light rain & Shower & $\begin{array}{l}\text { Organized } \\
\text { storm }\end{array}$ & $\begin{array}{l}\text { Unorganized } \\
\text { storm }\end{array}$ \\
\hline Decorrelation distance, D $(\mathrm{km})$ & 3 & 3 & 3 & 2 \\
Closest links, $n_{l}$ & 5 & 10 & 7 & 5 \\
\hline
\end{tabular}

Table 3. Optimum parameters of the algorithm obtained in the sensitivity analysis. 